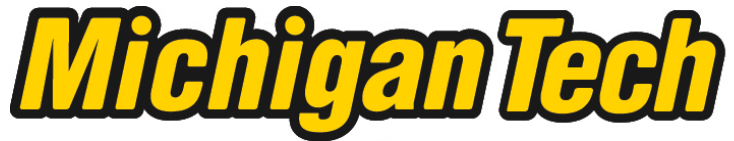 \\ Michigan Technological University Create the Future Digital Commons @ Michigan Tech
}

Dissertations, Master's Theses and Master's Reports - Open

Dissertations, Master's Theses and Master's

Reports

2014

\section{The study of agricultural non-point source pollution control policy system}

Qin Xu

Michigan Technological University

Follow this and additional works at: https://digitalcommons.mtu.edu/etds

Part of the Agricultural and Resource Economics Commons, and the Natural Resource Economics Commons

Copyright 2014 Qin Xu

\section{Recommended Citation}

Xu, Qin, "The study of agricultural non-point source pollution control policy system", Master's Thesis, Michigan Technological University, 2014.

https://doi.org/10.37099/mtu.dc.etds/750

Follow this and additional works at: https://digitalcommons.mtu.edu/etds

Part of the Agricultural and Resource Economics Commons, and the Natural Resource Economics Commons 
THE STUDY OF AGRICULTURAL NON-POINT SOURCE POLLUTION CONTROL POLICY SYSTEM

\author{
By \\ Qin Xu \\ A THESIS \\ Submitted in partial fulfillment of the requirements for the degree of \\ MASTER OF SCIENCE
}

In Applied Natural Resource Economics

MICHIGAN TECHNOLOGICAL UNIVERSITY

2014 
This thesis has been approved in partial fulfillment of the requirements for the Degree of MASTER OF SCIENCE in Apply Natural Resource Economics.

School of Business and Economics

Thesis Advisor: $\quad$ Dr. Gary Campbell

Committee Member: $\quad$ Dr. Shiliang $W u$

Committee Member: Dr. Mark Roberts

School Dean: Dr. Gene Klippel 


\section{Catalogue}

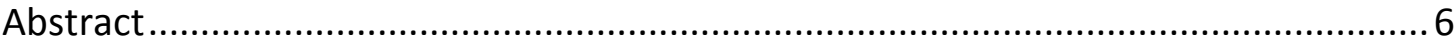

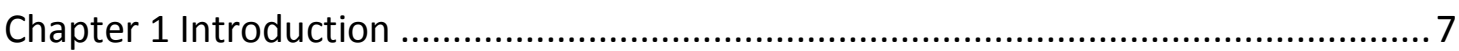

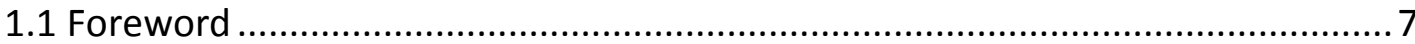

1.2 Research purpose, content and significance .................................................. 10

Chapter 2 Non-point source pollution ...................................................................... 13

2. 1 Concept and features of Non-point source pollution ........................................13

2.2 Agricultural non-point source pollution situations and hazards ........................13

2.3 The literature review of Agricultural Non-point Source Pollution.......................17

2.3.1 The progress of research on the basic theory of agricultural non-point

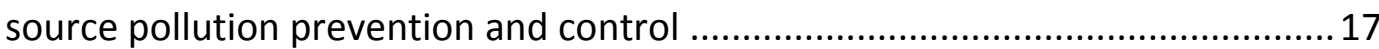

2.3.2 The progress of the study of influencing factors of ANPSP........................... 19

2.3.3 The progress of technical models and evaluation of ANPSP.......................20

2.3.4 Progress of research on comprehensive rural environment pollution control

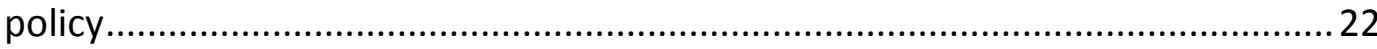

2.4 The main problems of agricultural non-point source pollution prevention and

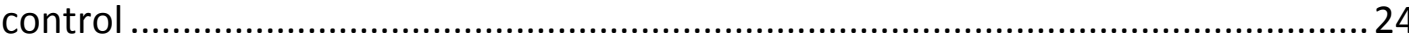

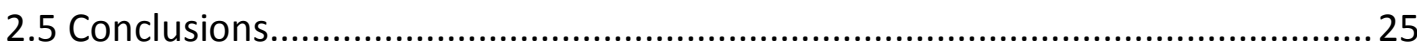

Chapter 3 Agricultural non-point source pollution control policy system ....................26

3.1 International experiences of agricultural non-point source pollution control ...26

3.1.1 The experience of reasonable application of pesticides and fertilizers.......26

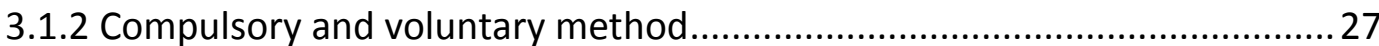

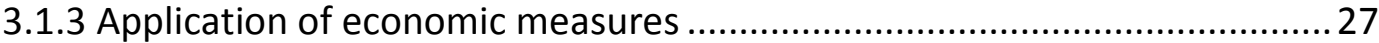

3.2 Evaluation of non-point source pollution control policy ...................................2.

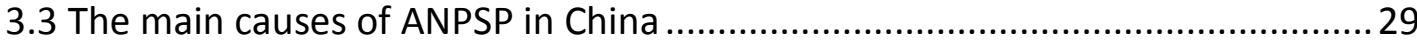

3.4 The frame of agricultural non-point source pollution control policy system in China. 


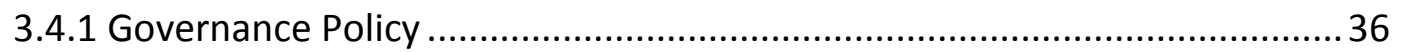

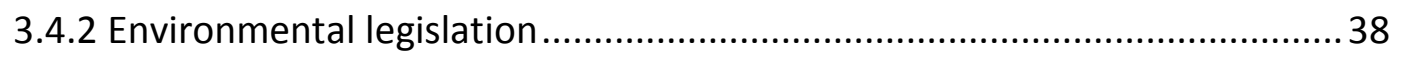

3.4.3 Technical system..................................................................................... 41

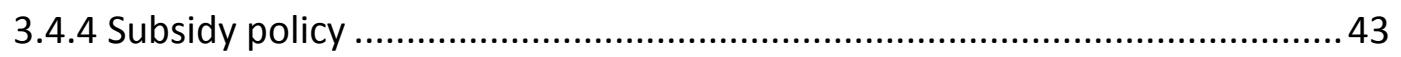

3.4.5 The advantages of the policy model ...........................................................49

3.5 Conclusion and enlightenment …………........................................................ 51

Chapter 4 Analysis of natural ecological structure of Qiandao Lake............................ 52

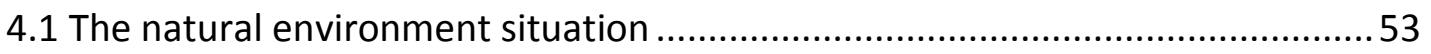

4.1.1 The geographical location and the hydrological characteristics...................53

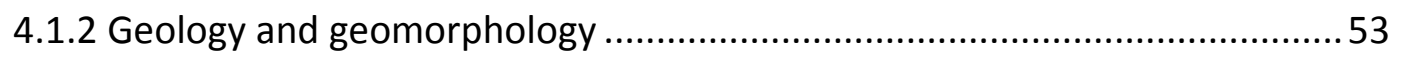

4.1.3 Meteorology and water temperature .......................................................... 54

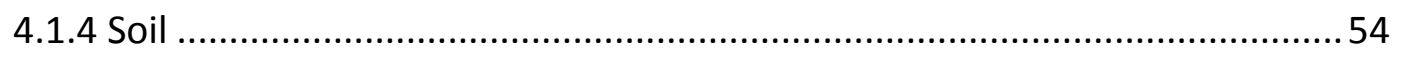

4.2 Current situations of social and economic development .....................................54

4.2.1 The administrative division and population ................................................ 55

4.2.2 Industrial and agricultural economy .............................................................5

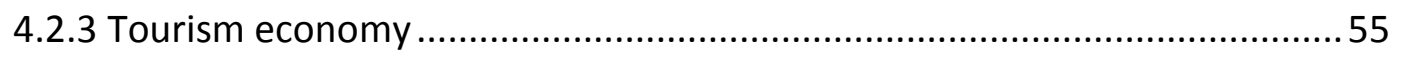

4.3 Present situations of ecological environment …….............................................5

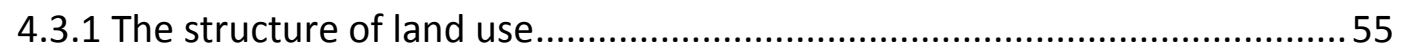

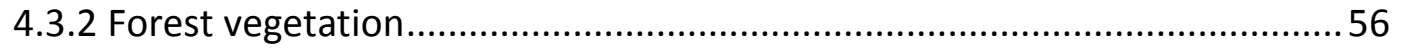

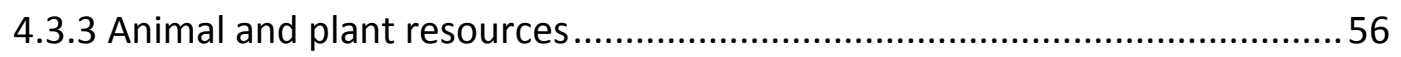

4.4 The situation of non-point source pollution of Lake Qiandao and reasons ........56

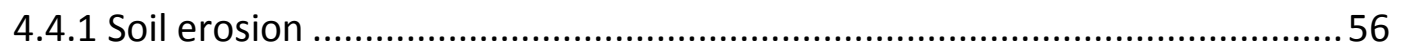

4.4.2 Chemical fertilizer pollution ........................................................................ 57

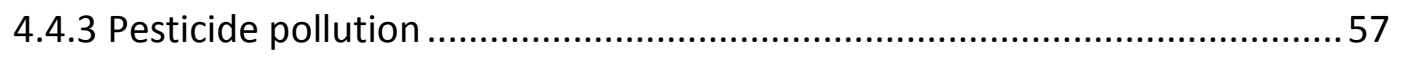

4.4.4 Lake eutrophication status ...................................................................... 58

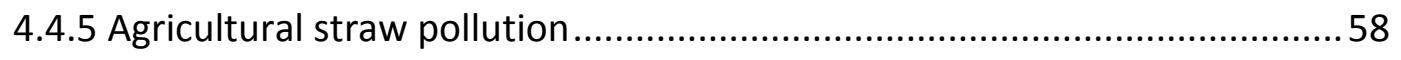

Chapter 5 Quantitative analysis of the relationship between the ASPSP and the soil

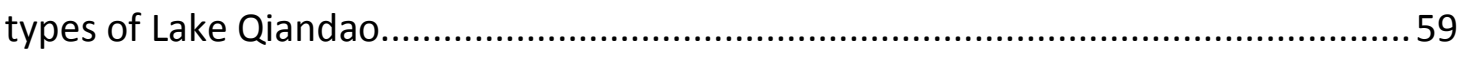




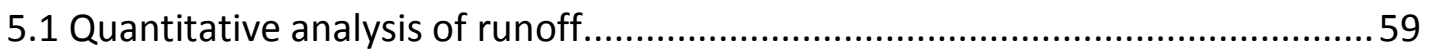

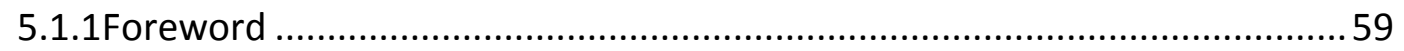

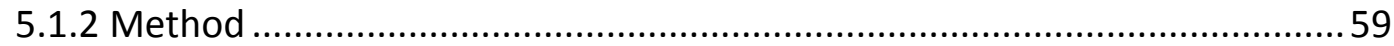

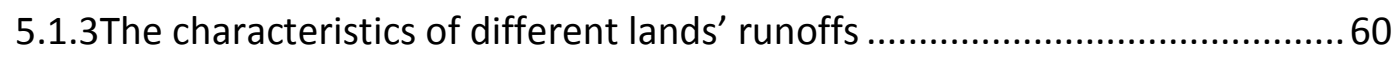

5.2 Nitrogen and phosphorus loss quantitative analysis .................................... 61

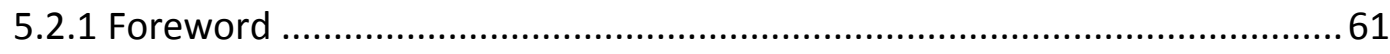

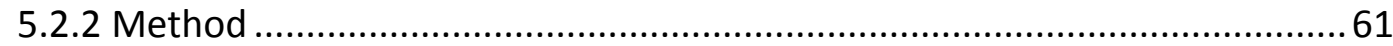

5.2.3 Nitrogen loss analysis in different land uses types. ................................61

5.2.4 Phosphorus loss analysis in different land uses types .............................63

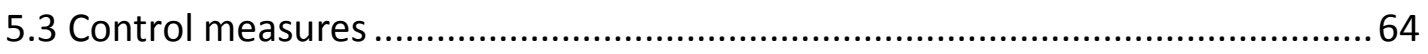

Chapter 6 Case analysis of agricultural non-point source pollution of Qiandao Lake .66

6.1 The main reasons and influence factors of ANPSP of Qiandao Lake..................66

6.2 Specific policy analysis of Qiandao Lake ..................................................... 67

6.2.1 The establishment of the goal of economic policy...................................68

6.2.2 The design principle and standard of the economic policy.........................68

6.3 The feasibility of economic policy for agricultural non-point source pollution.. 70

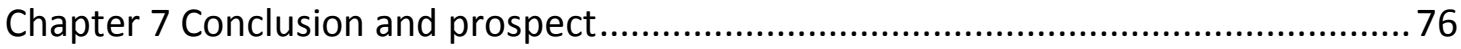

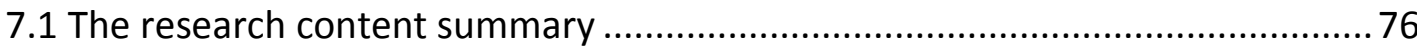

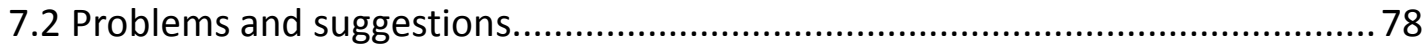

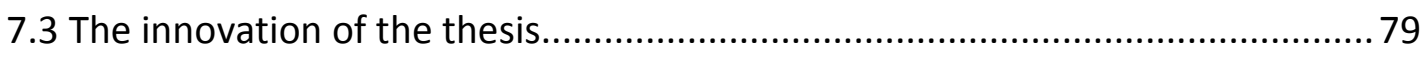

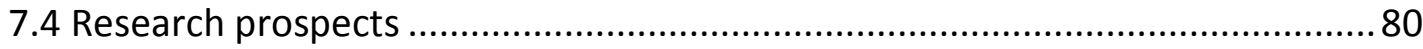

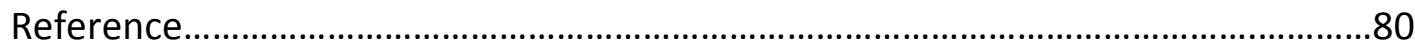




\section{Abstract}

As the agricultural non-point source pollution(ANPSP) has become the most significant threat for water environmental deterioration and lake eutrophication in China, more and more scientists and technologists are focusing on the control countermeasure and pollution mechanism of agricultural non-point source pollution. The unreasonable rural production structure and limited scientific management measures are the main reasons for acute ANSPS problems in China. At present, the problem for pollution control is a lack of specific regulations, which affects the government's management efficiency.

According to these characteristics and problems, this paper puts forward some corresponding policies. The status of the agricultural non-point source pollution of China is analyzed, and ANSPS prevention and control model is provided based on governance policy, environmental legislation, technical system and subsidy policy. At last, the case analysis of Qiandao Lake is given, and an economic policy is adopted based on its situation.

Keywords: Agricultural non-point resource pollution, Lake Qiandao watershed, ANPSP control model, subsidy policy. 


\section{Chapter 1 Introduction}

\subsection{Foreword}

Water is extremely important for human survival and development. Lakes are indispensable natural resources for food production of human society. However, the quality of water is getting worse and worse because of population growth, the rapid development of industry, agriculture, animal husbandry, and nitrogen and phosphorus emissions. All of these pollution sources lead to deterioration and eutrophication in water quality, which put a threat to human life. The sources of pollutants can be divided into two categories, the point source and the non-point source. Point source is from urban sewage and industrial pollution in the lake and watershed. Non-point source is from farmland runoff, intensive livestock, rural sewage and soil loss. Compared with point resource pollution which comes from a concentrated area, nonpoint resource pollution originates from a decentralized zone. It is not easy to identify and determine the geographic boundaries for the non-point source; therefore identification, prevention and management are very difficult. In recent years, with the increasing point source pollution control level, non-point source pollution problems have become more and more serious. Among all kinds of non-point source pollution problems, agricultural non-point source pollution problems have become one of the most hidden and difficult problems for pollution control. At present, the key to solve the non-point source pollution problems in China is not a lack of determination, confidence and control technology, but a lack of efficient policy design and the related management system.

China is a country with more than 20,000 lakes. The total water area is about over $70,000 \mathrm{~km}^{2}$, and the total water storage capacity is about 700 billion $\mathrm{m}^{3}$. In the past ten years, the trend of non-point source pollution has been increased in many lakes and reservoirs. The non-point source pollution was more serious in the river such as Qiandao Lake, Chao Lake and Tai Lake (Ailing 1999). The eutrophication of a lake is mainly caused by phosphorus nutrient salts and agricultural non-point source. At the same time, the proportion of agricultural non-point source pollution is on the rise. For instance, The runoff of fertilizer $\mathrm{N}$ and soil $\mathrm{N}$ from paddy fields in south China has been found to range from 6.75 to $27.0 \mathrm{~kg} \mathrm{~N} /\left(\mathrm{hm}^{2} \cdot \mathrm{a}\right)$, which is much higher than other countries. Livestock production developed very rapidly in China, resulting in the total livestock waste in 2002 being over four times greater than production of industrial organic pollutants. Moreover, the burning of straw in the open air causes additional smoke and dust pollution (Xing and Zhu 2000).

China began non-point source pollution research on the Qiandao Lake basin, Dianchi Lake and other places in the 1970s and has achieved some meaningful research results. 
However, there is still a lack of knowledge of hazards of non-point source pollution because of the reason that research work is not deep enough. Nationally, without research results for the agricultural non-point source pollution in water pollution and the basic mechanisms, there is a lack of the necessary scientific basis for the establishment of pollution prevention planning; policies and measures. Especially in China's Qiandao Lake Basin, the research on agricultural non-point source pollution is still empirical, and the research is just based on statistical estimation instead of the generation mechanism of agricultural non-point source pollution. Because of the different research method used, the results are quite different. But the basic problem is that there is a lack of systematic research and definite conclusion. Such as how much nutrient and sediment loss from farmland soil; the impact of the loss on eutrophication of Lake Qiandao; and the influence of different soil and agricultural management measures on sediment and nutrient loss.

After the pollution control program "zero" in 1998 (Environmental Protection Department of Chun'an County, 2000), a considerable part of the point source pollutions are under control in Lake Qiandao, but there is no significant improvement in the water quality. The government is not taking effective control measures for nonpoint source pollution certainly become one of the important reasons for bad water quality. As the non-point source pollution load is 50\% of the total load in Qiandao Lake, without effective implementation for non-point source pollution control is impossible to achieve a fundamental improvement of lake water quality (Chun'an 
County Environmental Protection Committee, 2000).

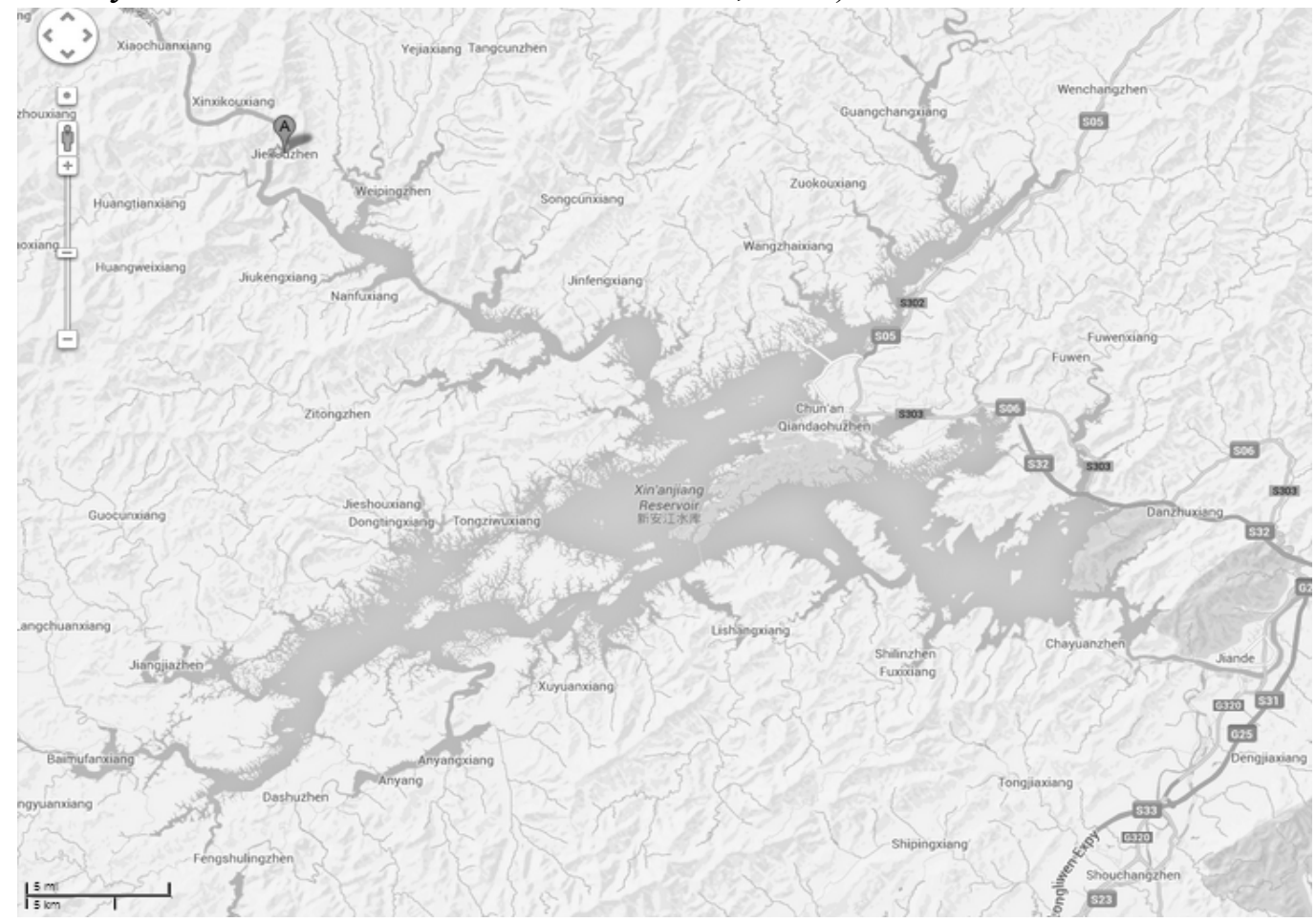

Figure 1 Situation and Location of Qiandao Lake (Map data @2013 AutoNavi, Google https://www.google.com/maps/place/Xin'anjiang+Reservoir/@29.5523395, 118.8745603, 9z/data=! 4m2! 3m1! 1s0x3449f130f12616f5:0x5b5df1aaecc07b18)

Qiandao Lake is called one of the best national tourism and formed by the Xin'anjiang Reservoir. The lake and its branches go across two provincial-level administrative regions, which make it locate in a significant strategic position. The lake is not only a source of drinking water for Zhejiang Province, is also the tactical reserve water in the Yangtze River Delta region of China. More than half of the rain collection area and water quantity of Qiandao Lake are in the territory of Anhui Province. There are a lot of researches on non-point source pollution of the other lakes in China, such as Tai Lake and Dianchi. However, studies of agricultural non-point source pollution of Qiandao Lake are less.

From the present research status of China, the existing literature on research methods and research contents of ANPSP are scattered and cannot form systematical and integrated management system. Since the lack of a theoretical basis, the establishment of non-point source pollution control policies is extremely difficult, which seriously lagging behind ANPSP control progress in China. At the same time, extant policy suggestions for ANPSP control are rarely considering the incentive mechanism and the cost effectiveness for policy making (achieve policy goals at the lowest cost), thus leading to low feasibility in practice. 
Europe and the United States began to attach importance to the research on management policy of agricultural non-point source pollution control since the early nineteen eighties, and they have made a lot of valuable achievements over the past 20 years. Normally the foreign policies of the agricultural non-point source pollution control mostly use an economic model for microscopic analysis. In view of the complexity of economic models and various assumptions of it, the policy bases on the collective performance just stayed in the theory stage and cannot been used in practice. Policies that are successfully implemented practically, such as the Best Management Practice and the point source-non-point source pollution trading plan policy, their function object are dry land, coupled with the different national conditions and cannot be directly moved to China.

Research report (Bo, 2012) pointed out: for the Chinese government, the key to solve the ANPSP problem is not a lack of related knowledge on non-point source pollution and is not a lack of pollution control technology. The main point of the problem lies in a lack of policy framework and supporting system; prevention method; the lack of a technical system for the publicity of non-point source pollution to farmers, which encourages and promotes farmers to adopt control technology and effective management method.

Therefore, on the basis of previous studies, the control of ANPSP is the major subject for rural development of China in the future, which is also one of problems need to deal within the process of building new countryside. Given the current situation of scarcity of ANPSP control policy, this study attempts to explore management pattern and cost effective policy framework in the long term combined with existing research results in the field of agriculture, environment and information science. It is mainly from the perspective of environmental economics and management research of agricultural non-point source pollution control and comprehensive management. At the same time, the designed policy framework should be good for the application of natural science and technology and can provide important theoretical and decisionmaking basis for the related departments to formulate macro management policy.

It's expected that the research findings based on the spot can be used to other areas of Qiandao Lake and provide a scientific basis for controlling agricultural non-point source pollution and simply solving the problem of eutrophication in Qiandao Lake, eventually play an impelling action in comprehensive treatment to water pollution.

\subsection{Research purpose, content and significance 1.2.1 Research purpose}


In view of the characteristics and nature of agricultural non-point source pollution, this paper will preliminarily build a policy framework for agricultural non-point source pollution control and management based on the economy and society status in China. It is expected that the active attempt and the exploration of ASPSP control could help the policy designer for better decision making.

\subsubsection{The research content and ideas}

This paper makes a comprehensive analysis and summary for China's agricultural nonpoint source pollution status, characteristics and causes based on the related data and research results of domestic scholars. The paper uses the method of qualitative and quantitative analysis to build a policy framework for the agricultural non-point source pollution control and management through the methods of environmental science, environmental management, environmental policy, environmental economics, agricultural economics and absorbing the experience and results of management from foreign countries.

The main components of the model include the governance policy, which requires the government to adjust the self-sufficient rate of food and set up the technical organization for helping and guiding the farmers' behaviors. The environmental legislation requires the government to establish laws and regulations to control the organic waste emissions and promote the recycling of organic waste, while establishing laws for pesticide and fertilizer pollution control. The technical system advises to monitor the environmental capacity and quality of farmland and sets up a highly efficient technology promotion system while set up comprehensive research in the watershed of small scale. Subsidy policies include three aspects: the subsidies of a positive externality; the subsidies of reducing the negative externality and price subsidies.

At last, the paper selects Qiandao Lake Basin of Chun'an County as a demonstration zone and puts forward the watershed agricultural non-point source pollution control of economic policy according to the specific situation of the river basin on the theory basis of the policy frame. Moreover, the paper analyzes the feasibility of economic, technical and legal system.

\subsubsection{The significance of the research}


(1) This paper provides a theoretical basis for the environmental protection departments and policy makers to formulate non-point source pollution control and management measures, laws and regulations. The thesis promotes the development and implementation of agricultural non-point source pollution control and management of a comprehensive policy system. The thesis improves and integrates the existing system of water pollution control.

(2) This paper provides help and reference for a specific watershed agricultural nonpoint source pollution prevention and control policy. This study has certain theoretical and practical significance for China's effective control and management of agricultural non-point source pollution. 


\section{Chapter 2 Non-point source pollution}

Correctly grasping the influence factors and situation of agricultural non-point source pollution is the premise and basis for the establishment of effective pollution control policy. Therefore, this chapter has studied the grim situation, causes, characteristics and the progress of research on agricultural non-point source pollution.

\section{1 Concept and features of Non-point source pollution}

Non-point source pollution (NPSP) is also called diffused pollution (DP) or surface pollution. It is the opposite of point source pollution (PSP). Point source pollution comes from fixed sewage sources emissions from specific industrial urban source. Agricultural non-point source pollution is defined as pollution in aquifers, lakes, rivers, shore, atmospheric and ecosystem caused by sediment, pesticides, fertilizers, pathogens and other dispersed sources of pollution from non-specific locations in precipitation (or snowmelt) under the action of erosion by surface runoff, farmland drainage and ground leakage.

Compared with point resource pollution which comes from a concentrated area, nonpoint resource pollution originates in decentralized zone. It is not easy to identify and determine the geographic boundaries of the source. So identification, prevention and management are very difficult.

Consequences of Agricultural non-point source pollution are often very serious. The paddy field is the biggest source of pollution in Lake Biswa, Japan. 94\% of the nitrogen load and $52 \%$ of the phosphorus load are caused by non-point source pollution in Denmark's 270 rivers (Xing and Zhu 2000). The runoff of fertilizer N and soil $\mathrm{N}$ from paddy fields in south China has been found to range from 6.75 to $27.0 \mathrm{~kg}$ $\mathrm{N} /(\mathrm{hm} 2 \cdot \mathrm{a})$. Livestock production developed very rapidly in China, resulting in the total livestock waste in 2002 being over four times greater than production of industrial organic pollutants. Moreover, the burning of straw in the open air causes additional smoke and dust pollution (Xu Y 2007). 15\% of the lake water quality is deteriorated in Austria, while the agricultural non-point source emissions of phosphorus and nitrogen are the largest share in various pollution sources, and the total emissions are more than $65 \%$ (Xingming, 2011).

Agricultural pollution and livestock breeding pollution have increased year by year and became increasingly prominent pollution problem. Statistics of Tai Lake in 1995 shows that, without considering the contribution of precipitation and dust, the nonpoint source nitrogen and phosphorus are accounting for $55 \%$ and $28 \%$ of the total nitrogen and phosphorus. With the exception of agricultural fertilizer, livestock 
breeding pollution and aquaculture pollution have been comparable to the industrial pollution (Lishan 1997). Asian Development Bank pointed out that the agricultural non-point source pollution leads $0.5 \%-1 \%$ direct economic losses to the Chinese GDP (Zailan, 2012). Although agricultural non-point source pollution control research has already been launched and made many research results, from the research results of China and other countries, focus and content are mainly concentrated in two aspects: biological engineering technology and engineering management technology. The management policy relative is less.

Biological engineering measures and engineering management technology reduce nonpoint source pollution through physical, chemical or biological methods. Non-point source pollution control system includes retention of the Best Management Practice. The government strengthens the protection of the water environment of farmland area and set up purifying pond sewage ecological treatment system, which is of low cost and small occupation area. Also, the government purified farmland water pollutants through cultivated wetland and aquatic plants.

In the aspect of the policy, the government controls pollution behaviors through laws and regulations. The measures are basing on positive encouragement and using regulation as a supplement. Agriculture is the foundation industry of China, so dogmatically using the "polluter pays" principle is improper. Non-point source pollution control policies of rural areas should become "industry nurturing agriculture and the cities support the countryside". The basic direction of policy making is giving positive encouragement to farmers and using regulation as a supplement.

\subsection{Agricultural non-point source pollution situations and hazards}

Currently, many countries have agricultural non-point source pollution, and it is one of the main causes for water pollution. A survey of the United States Environmental Protection Agency shows that agricultural non-point source pollution is the main pollution source of the United States in 2010. It not only causes quality degradation of $40 \%$ of the lakes, also causes deterioration in groundwater and wetland (US Environmental Protection Agency, 2010). In European countries, agricultural nonpoint source pollution is also the main source of pollution of water. Especially, it is the main source of nitrate pollution for groundwater and the most important reason for phosphorus enrichment in surface water. According to statistics, agricultural non-point source pollution of phosphorus is accounting for $24 \%-71 \%$ of the total load of surface water pollution (Lena 1994). In Ireland, there is no obvious point source pollution in most lakes. The pollution sources that lead to eutrophication mostly come from nonpoint source pollution (Foy and Whithers 1995). In Finland, the percentage of agricultural non-point source emissions of phosphorus and nitrogen in various 
pollution sources is the largest, which is accounting for more than $50 \%$ of total emissions (Sharpley et al. 1994). In China, the non-point source pollution situation is not optimistic. Rapid urbanization, fertilizer use, pesticide use have increased dramatically, thus making non-point source pollution of the water environment an increasingly prominent problem. In China, ecological damage caused by years of human activity is leading to serious soil erosion. The chemical fertilizer utilization rate of China is only at an average of $30 \%-35 \%$, so the remaining fertilizer flows into the environment, water and soil (Hongxiang et al. 2005). The loss of nitrogen fertilizer rate is higher. In Beijing Miyun Reservoir, Tianjin Bridge Reservoir, Chao Lake of Anhui, Erhai Lake of Yunnan, Dianshan Lake of Shanghai, the proportion of non-point source pollution is higher than point source pollution (Quansheng 1997). According to the investigation of the basin of Taihu, Chaohu and Dianchi, the contribution of industrial wastewater accounts for only $10 \%-16 \%$ of total nitrogen and phosphorus pollution and mostly the water pollution is caused by sewage and agricultural nonpoint source pollution (Chinese Department of Environment Protection 2000). Investigation found that, the soil loss in China each year is up to 5 billion $t$ and the $\mathrm{N}$, $\mathrm{P}, \mathrm{K}$ elements and other nutrients of the losing soil is equivalent to the national annual fertilizer use amount. All of these losses leading a considerable part of pollutants flow into the water, river and the aquatic environment (Hongliang 1990). Excessive aquaculture has increased water pollution pressure. In 2012, according to statistics in Taihu, only about $30 \%$ of the food is consumed by fish, and the rest is fermented. However, there is only $9 \%$ of nitrogen and phosphorus has been used in the $30 \%$ fish food, and the rest of $\mathrm{N}$ and $\mathrm{P}$ are discharged into the lake. Currently, the area of aquaculture is $20,000 \mathrm{hm}^{2}$ in Taihu and the aquaculture pollution is accounting for $74 \%$ of the total water pollution (Fujian and Minghua, 2012)

Agricultural non-point source pollution has an impact on the $30 \%-50 \%$ of world's land area. It is about $12 \%$ of 1.2 billion $\mathrm{hm}^{2}$ degraded lands in the world are caused by agricultural non-point source pollution (Weaver and Reed 1998). Non-point source pollution has become the main source of threatening to surface water. Excessive fertilization, improper fertilization structure, agricultural drainage and a series of additional factors exacerbate the occurrence of eutrophication. Deterioration caused by the eutrophication of water quality and ecological destruction is seriously restricting the sustained and healthy development of the national economy (Huanlei 1996). Nonpoint source pollution has become a research topic to be explored in China (Quansheng and Huaer 1996).

The numerous sources of agricultural non-point source pollution carry a lot of sediments, nutrients, toxic and hazardous substances into rivers, lakes and reservoirs, which are causing suspended solids and N, P concentrations, toxic and hazardous substances content to increase and to lead to eutrophication and acidification. 
Agricultural non-point source pollution can be described as the ecological impact related to the whole human-centered environment. For example, agricultural nitrogen emissions will lead to eutrophication and decrease drinking water quality and damage human health. Nitrogen is one of the most important nutrients that can lead to eutrophication. The body of water in the event of eutrophication has algae, abnormal reproduction and water turbidity of aquatic organism, which reduces transparency and leads intensity and depth of sunlight to decrease. Dissolved oxygen is also decreased, and a large number of aquatic organisms die, so aquatic ecosystems, and water feature have been seriously damaged. This directly affects the safety of drinking water and supply of industrial water, thus posing a threat to human health and aquaculture (Yang 2004). Water environment has become the main object of non-point source pollution and the pollution mainly has the following two aspects:

\section{(1) Nutrient pollutants in the aquatic environment}

Eutrophication usually is that the velocity of lakes, reservoirs and other closed or semiclosed water bodies is less than $1 \mathrm{~m} / \mathrm{min}$, and there are nitrogen, phosphorus and other nutrients enrichment in rivers. All of these are resulting in a reduction of dissolved oxygen in a water body, along with a large number of dead aquatic organisms.

The main source of water nutrients (nitrogen and phosphorus) is urban sewage, industrial wastewater and agricultural nitrogen and phosphorus. Among them, farmland nitrogen and phosphorus loss are the principal reason for eutrophication (Dago and Hessenetal 1997). In the United States, non-point source pollution is identified and measured in the early years. The conclusion is that the agriculture is a major reason for non-point source pollution. Agricultural runoffs lead $64 \%$ of the rivers and $57 \%$ of the lakes to be polluted in US. China's third largest freshwater lake Taihu has a serious problem of eutrophication. Eutrophication of Taihu is mainly caused by industrial and agricultural sewage (Lu 1998).

(2) Toxic pollutants in the aquatic environment temporary

According to the United States, Japan and other countries reported, even if the point source pollution achieve zero emissions, the compliance rate of river water is only $65 \%$, the compliance rate of the water quality of the lake is only $42 \%$ (Sha 2011). This is because except for point sources, there are still a lot of non-point source pollutants in widely and continuously flows into the water. Research in many countries and regions has proved that the problem of toxic pollutants in the water has become increasingly prominent and the agricultural non-point source pollution accounts for the largest amounts.

Toxic pollutants are mainly caused by pesticides, herbicides and their degradation products, heavy metals of fertilizers and other toxic organic compounds. Its direct 
effect is causing acute poisoning to water organisms. There are countless types of toxic pollutants such as organic phosphorus pesticides, organic chlorine pesticides, cadmium, and other heavy metals in phosphate fertilizer. All of these contaminants in the aquatic environment will ultimately have negative effects on humans.

\subsection{The literature review of Agricultural Non-point Source Pollution}

The research progress of agricultural, environmental pollution control is very broad and can be summed up in the following 4 aspects: 1) the basic theory research on the agricultural non-point source pollution prevention and control.2) the influence factors of agricultural non-point source pollution in rural areas based on the different levels.3) The process of technical models and evaluation of ANPSP .4) the agricultural nonpoint source pollution prevention and control mechanism and policy research.

\subsubsection{The progress of research on the basic theory of agricultural non- point source pollution prevention and control}

In developed countries, especially in the United States, study history of non-point source pollution is very long and active. It is believed that Arthur Pigou was the first scholar to study the problem of non-point source pollution from the angle of economics systematically. Thanks to his study on externality theory, economists have begun to pay attention to the non-point source pollution problems in rural areas since the1960's and the externality is regarded as a theory basis in the analysis of non-point source pollution problem (Anthony 1981). At present, in North America and EU countries, the basic economic research for agricultural non-point source pollution prevention and control has been involved in external property, public goods, fiscal and tax theory. At the same time, a large number of relevant research tools and analytical models have been developed, such as HSPF, AnnAGNPS and SWAT (Linfeng 2011).

The prevention and control knowledge and basic theory research of ANPSP start late in China. In the 1950's -1960's, rural areas throughout China actively carried out the farming production in the background of food is the basis of a country, but because the production technology is relatively backward and the demand for food is urgent, people ignored the coordination between environment protection and economic development in food production, so there are a lot of agricultural inputs, such as pesticide and fertilizer and the pollution emissions were met everywhere. The 1970s' is the start of the elementary theory of agricultural pollution prevention and control in China (Fan 1998). At that time, people in rural areas are beginning to feel the environment around them has suffered different degrees of pollution, and the production causes some adverse impact on their life. Some domestic scholars began carrying out a lot of investigations on rural areas and putting forward some basic ideas 
for prevention and control of agricultural pollution in the rural area (Hongfu 2005). These theories are put forward based on the reflection of rural environmental problems and the experience from developed countries on environmental governance. Regardless of the fact that they are still in infancy, they have a profound influence on the future study of specialization. In the late 1990 's, the environment pollution in rural areas has become a serious problem. Researcher has started from the problems of agricultural non-point source pollution to proceed with the study. At present, from the massive domestic literatures of ANPSP prevention and control, the scholars' researches on the basic theory of ANPSP pollution and control are relatively less and mostly focusing on a simple economic theory analysis. They are mainly summarized in the following two aspects:

(1) Analysis based on institutional economics. Dayong Hong thinks that China's existing dual structure of the social system and long-term ineffective control of the agricultural non-point source pollution is closely related to each other (Dayong 2004). Yunsong Lu points that the reason of the increasing environmental pollution in China is because of no coordination of economic development between urban and rural area (Yunsong 2009). The breaking of the urban and rural economic made the poverty more conspicuous. Farmers faced enormous pressure to survive and improve life, thus not taking into account of the environmental pollution control. Haiyan $\mathrm{Wu}$ also pointed out that the reason of ANPSP in rural areas is complex, but the root of all problems is that the incentive and constraint mechanism is not integrated (Haiyan 2009).

(2) Based on the analysis of microeconomics. This research mainly involves the external analysis, social economic factors and economic loss evaluation of agricultural non-point source pollution problems. Yonghui Zhao and Zhihong Tian studied the methods and policies of reducing pesticide pollution in China by using externality theory (Yonghui and Zhihong 2005). Yali Lu and Huifeng Xue got the conclusion that the government lacks the security system and incentive and restraint mechanisms corresponding to the agricultural non-point source pollution control through the method of game theory (Yali and Huifeng 2007). From the perspective of economic analysis, Jie Shang considers that the causes of agricultural non-point source pollution are mainly due to the common effects of market failure and government failure (Jie 2007). There are problems of serious system obstacle and specific implementation issues of the prevention and control of ANPSP in China's rural areas. The reasons are the lack of effective management system and economic incentive mechanism for pollution prevention. At the same time, the main role of farmers to participate in the environmental protection and control was ignored. 


\subsubsection{The progress of the study for influencing factors of ANPSP}

The study of influencing factors of ANPSP is derived from water pollution problem. In the 1960's, some developed countries, such as Britain and America started the study first. In the late 1970's, the initial research of influence factors and macrocharacteristics started to shift from the related factors analysis and spatial variability analysis to the main control factor analysis and spatial analysis of critical source areas (Ping 2008). After the 1980's, research of influence factors of ANPSP went more deeply, especially with the development of computer and satellite remote sensing technology (Weiguang and Yi 1999). Therefore, the study of ANPSP in foreign rural areas is gradually turning into the extension type, application type, and combining with the regional features and trying to explore the effect of new pollution factor.

With the increasingly serious environmental problems caused by rapid development of China's rural economy, researchers began to notice that the study of quality status of the rural environment is deepening, and the exploration of the rural environmental pollution from different perspectives is particularly necessary. Domestic scholars mainly study the issue from the following three aspects:

(1) Study of the influence factors of ANPSP from the perspective of the micro.

Scholars mainly study the influence of the rural household economic behavior on ANPSP prevention and control. Especially the study of the response of household production and business activities and life style to environmental policy has become a research focus in this field. Lihua Zhou (Lihua 2002) and Yan Ma (Yan 2007) are agreed that the rural environmental quality deterioration is directly related to the farmer's production behavior and way of life. Xiaofang Yue found that the reason of unreasonable rural environmental behavior is the change of consumption structure of rural energy. Large pollutant emissions and less knowledge of ANPSP is the root. Hongxia Qin (Hongxia 2006) used the social methodology and anthropology to study the lifestyle of the farmers and rural environment of Sheyang County of Jiangsu Province and got the following conclusions:1)before the 1990s, due to the level of economic development and the influence of consumption concept, people's lifestyle has less harm on agricultural non-point source pollution.2) after the 1990's, the changes in the development of the rural economy, the way of life and the lag of rural environmental management are leading to the rural environmental degradation and pollution. In the aspect of quantitative analysis of the farmer's behavior on ANPSP, currently the scholars think it is necessary to establish bio-economic household model, which connects the household economic behavior model and ecological economic model together (Minjun and Tao 2012).

(2) Study of the influence factors of ANPSP based on the meso perspective. 
Scholars believe that, many factors can lead to environment pollution and the factors of different regions involved are different. The classification of influence rate of the factors in a specific area has very positive significance for the prevention and control of ANPSP in rural areas. Therefore, special research for large scale regional rural pollution sources has started in recent years. Lizhong Xia thinks that water pollution load of nitrogen and phosphorus of rural residential area is an important source of ANPSP through the research on typical rural environment monitoring of Tai Lake (Lizhong 2003). Nengwang Chen summarizes the domestic sewage water quality and emission characteristics and quantitatively estimates the nutrient pollution load of rural wastewater in Jiulongjiang Basin (Nengwang 2004). He puts forward that the main reason of ANPSP in rural areas is the water body pollution. Liangmin Gao regarded the rural toilet as the research object and carried out the water quality monitoring of a river network. The results show that the toilet sewage in the rural area is an important part of non-point source pollution (Liangmin 2005). Jihong and shudong (2011) use statistical data of Jiangsu Province from year 1978 -2009 to analyze the economic factors of ANSPS. The study shows that the development of agriculture technology and the establishment of ANSPS control policy can effectively reduce the emissions of ANSPS, which means the development of the agriculture economy and the environment quality can affect each other.

(3) Study of the influence factors of ANPSP based on the macro perspective.

Research on this scale is carried out mainly based on the contemporary rural construction. Rui Hou thinks that except for the three aspects of social culture, society and economy, the lag of science and technology is one of the most important factors that affect the rural environment in China (Rui 2000). Zixia Hu pointed out that the crop production and livestock breeding are common factors cause ANPSP (Zixia 2006). Yang Su thinks that the ANPSP should be summarized into three categories in the process of rural modernization. They are the modernization of farming production brings all kinds of pollution, the residential pollution caused by infrastructure construction and environmental management lag and industrial pollution caused by the improper layout of enterprises and governance (Yang S 2006). Xiaodong Zhu pointed out that the ANPSP is an important factor that restricting the building of a modern countryside. The city industrial structure transition, the rapid development of enterprises, large-scale livestock breeding and backwardness of cultivation technology is the main factors causing ANPSP (Xiaodong 2008).

\subsubsection{The progress of technical models and evaluation of ANPSP}

The quantitative study of ANPSP has been mature in the 1970's, and the Universal Soil Loss Equation (USLE) was given by the US Soil Conservation Service. The Water Pollution Control Act Amendments of the United States mark a major turning 
point in the progress of non-point source pollution in 1972. This law has greatly promoted U.S. non-point source pollution studies to be carried out and a lot of influential non-point source pollution models to be provided.

Non-point source pollution model can be divided into four stages (Binghui and yongze 1994): Stage 1 is before the computer era, which is between 1950s and 1960s. A number of mathematical models have been developed at this stage, which are including SCS curve hydrological model and USLE. Stage 2 covers the entire 1960s and computer models began to appear at this stage. Stage 2 is commonly referred to as the golden age of Hydrology. However, due to the high cost of computers, only a few of universities and institutions were in the development of such a model. One of the most successful models is the Stanford Watershed Model (Ailing and yanming 1997). Stage 3 is from the 1970s to the 1980s. In the mid 1970s, non-point source model was in great development. This period is mostly based on hydrological-mathematical model to monitor non-point source pollution. In the non-point source pollution management, a mature BMPs (Best Management Practices) was gradually formed during this period. In the late 1970 s, the main focus of the study shifted from the application and management of existing model on non-point source pollution to the development of new practical model for study and implementation of non-point source pollution control and management measures. Stage 4 is from the late 1980s to the present. Owing to the widespread of PC, some features of the models have improved gradually to be applied to general PC or workstation. Combined with the GIS, the model gradually evolved into a composite model with improving the model input output capabilities and operational efficiency (Long Z and Jipin 1998).

Foreign agricultural non-point source model is mostly associated with soil erosion model together and shown as a watershed model. Various models can be operated in a GIS platform or combined with GIS. Some commonly used models are RUSLE, CREAMS, AGNPS, SWAT, WEPP, ANSWERS, etc

China has also made a lot of studies about the technical models, such as USLE (Yansheng 1990). USLE is widely used in soil erosion, environmental assessment and other aspects of water quality evaluation in Dian Chi (Zhaxian 1994). ANSWERS model also has been applied in many areas of China. For example, Yibing Chen used the ANSWERS model for implementation of a small watershed simulation and combined ARC/IFO with GIS to simulate soil loss in the case of light rain, moderate rain, and heavy rain process in purple hilly area of Sichuan (Yibing 1998). SWAT is a long period, basin distributed and continuous physical model. It is developed by the U.S. Department of Agriculture and mainly used to predict the effects of large-scale watershed management practices on water quality and sediment. The Model can simulate the general watershed hydrological processes, such as sediment in channels and chemicals loss, etc. In China, it also applied in Luxi watersheds of Pingxiang City 
in Jiangxi, northwestern Gansu Heihe River Basin and other regions (Zhonge et al. 2003). In the aspect of model application and development in China, due to the limited data and the technique, most of the models are not got according to the actual contaminant migration in the areas of earth's surface. Mostly the model is empirical statistical model based on the receiving water quality analysis and the calculation is using the hydrological model and rainfall runoff pollution load estimation method (Xiping 2012)

Integrated non-point source pollution model is a typical study of the occurrence, migration and transformation of non-point source pollution from the mechanism. So its scope is much broader than the empirical model. However, its structure is often more complex and requires a large number of model parameters, which limits the widespread application of the model in a certain extent.

\subsubsection{Progress of research on comprehensive rural environment pollution control policy}

Since the 1960's, a few developed countries such as the United States and Europe began to focus on the agricultural non-point source pollution prevention and control policy. United States of America emphasized the importance of non-point source pollution in the Clean Water Act of 1972 and put forward that the government provided some financial support for non-point source pollution control. Subsequently, the United States has issued a series of legislation for non-point source pollution and even made laws for agricultural non-point source pollution prevention and control (Dongmei 2008).

In recent years, many countries have gradually tended to integrate control method with the management policy, and have promulgated and implemented a number of policies and regulations for agricultural non-point source pollution prevention and control management (Line 1994). At present, the focus of foreign countries in this field is reducing non-point pollution through controlling the total pollution loads, reasonable pollution load distribution; extensive using economic means (such as taxes, subsidies, emission's trading right and so on) in the context of the established ecological capacity; and finally putting forward the specific project design. From the American history, the water quality control policy is rarely mandatory. The policy that established on the basis of the 'carrot' policy tool is used frequently, and the so-called carrot refers to some voluntary project or program. In Western Europe, the most important change of environmental regulation is the frequent use of voluntary agreement ( $\mathrm{Wu} 2012)$

Randall and Taylor (2011) pointed out that the negotiation protocol (negotiated agreement) has become a very popular policy tool since the early 1980's. Negotiation protocol is formed between the manager and the managed enterprise or industry. Different from the traditional unilateral regulation, the managers and the managed 
industry on both sides has an influence on the policy. The formation of this policy has been widely used in the field of the environment, including agriculture.

Braden and Segerson (1993) pointed out that the spatial difference of non-point source pollution is leading to considerable spatial variability of the economic incentive policies and measures. It also leads to economic incentive measures of great differences in flexibility, effectiveness and technology choice cost of reducing the pollution, which limits the applicability to adopt a unified measure to control non-point source pollution problems to a great extent. Dubgard (1995) compared the input tax with limiting the input amount, the results show that the administrative cost of the second measures is cheaper, and the input tax is more flexible and cost effective.

James (1998) put forward that pay subsidies to implementation of the positive externalities, such as the application of organic fertilizer. If the opportunity cost of implementation of the plan is different among the farmers, unified payment rate is not efficient. Dubgard (1999) pointed out that the pesticide tax will lead to the fact. Namely the pesticide of high poison is cheaper, thus leading to increased use of this pesticide. Therefore, Dubgard advised that the government should fix the agricultural tax through the use of reasonable index based on the environmental impact weight of pesticide.

Aiming at the problem of ANPSP occurs widely in the rural area of China. Domestic scholars mainly put forward pollution prevention and control measures in the following three aspects:

The first one is concentrating on the specific environmental problems in rural areas, such as environmental problems of water resources; agricultural non-point source pollution problems, and put forward pollution control measures from the technical aspect.

The second is from the angle of sociology to explore the environmental rights and environmental awareness of the rural population. Scholars pointed that the improvement of farmers' environmental awareness is an important measure to solve the current problems of agricultural non-point source pollution.

The third is from the perspective of environmental economics, scholars pointed out that the active government intervention behavior is the most effective means for prevention and control of ANPSP in rural areas. At the same time, the lever of price intervention is also essential. Such as Lizhi Zhu (Lizhi et al. 2007), Lian Zhu (2005), Pingan Xiang (Pingan at al. 2007), Jianchang Liu (Jianchang et al. 2005), and Zhengyong Yang (2004 )put forward the pollution prevention and control of the environmental policy and economic means based on their research from the fiscal and market compensation mechanism, ecological control, emission's trading system of 
chemical fertilizer and pesticide, taxation, insurance and subsidies, product cost, liability and mortgage refund policy, pollution prevention and control policy and the government behavior selection mechanism. Xinliang (2011) pointed that, with the effective control of point source pollution, the non-point source pollution has become the main reason of water eutrophication. Then he put forward some prevention and control policy according to the situation source and characteristics of ANSPS.

\subsection{The main problems of agricultural non-point source pollution prevention and control}

Based on previous analysis, it is not difficult to find that although the prevention and control for ANPSP and its corresponding theory have made great progress in rural areas of China, it is still a big gap between the requirements for sustainable development of the rural society. As everyone knows, comprehensive research on the ecological environment construction in rural areas is systems engineering with multilevels, multi-objects and multi-tasks. The principle must follow the ecology, economics and system engineering, which are increasing the difficulties of controlling. Although predecessors have made a lot of very fruitful work in this field, there are still a lot of problems as follows:

(1) The study of the theory system is not integrated. Despite the fact that domestic scholars have many necessary discussions on the theoretical foundation of ANPSP control of rural areas, domestic scholars do not publish papers for rural environmental pollution prevention theory. At the same time, scholars' papers of the principle and control methodology of ANPSP focus on one field. Also, their studies lack a unified standard and timely summary.

(2) The spatial scale selection of studies is different, thus leading to different conclusions. At present, scholars mainly focus on the large scale rural areas of a province and even a country. The systematic research on ANPSP control of specific middle and small scale areas is obviously insufficient. Through the research, it is not difficult to find that research on different spatial scale will directly lead to different impacting ways and different impacting intensity of the agricultural factors. Social economic factors are highly dynamic and easy to change, but the factors of natural resource are relatively stable and have a cumulative effect. Generally, in a larger scale, the factors of economic, institutional, policy and population reflect more obvious. In small and medium scale, the economic factor is more important. Therefore, studies should include the knowledge and method of comprehensive natural and social science.

(3) Policy and legislation for agricultural non-point source pollution are insufficient. For non-point source pollution, the improvement of the supervision system of source control and the corresponding mechanism is very important. Some developed countries 
in Europe and America, the supervision over the technical implementation standard of the agricultural non-point source pollution control is mainly through the government funding. But in China, at present there is no supervision system and the corresponding incentive measures to guide the behavior of farmers and rural agricultural supply, no matter in the water source protection area or serious water pollution area.

\subsection{Conclusions}

Analysis results show that China's water pollution load of non-point source pollution, especially the agricultural non-point source pollution plays an increasingly large proportion. Agricultural non-point source pollution is widely distributed in China, and its load ratio has been close to or more than $50 \%$, which constitutes a serious threat to surface water and groundwater quality of China.

Further studies show that, due to the different natural conditions and social production status of basins in China, the agricultural non-point source pollution also has different types and features. But on the whole, China's agricultural non-point source pollution is caused by unreasonable land use and production, soil erosion; agricultural chemicals applied blindly, large-scale livestock breeding pollution of rural life, indiscriminate discharge of wastewater and rubbish, etc.

The approach of human behavior depends largely on the policy guidance. However, China's agricultural policy and environmental management are disconnected for a long time. Especially they lack laws and regulations and measures to supervise agricultural non-point source pollution from the government, which is an important reason that agricultural non-point source pollution have existed and aggravated in China. In order to control the growing of agricultural non-point source pollution, formulation and implementation of flexible economic incentive policies for ANPSP control and management in different regions are urgently necessary. 


\section{Chapter 3 Agricultural non-point source pollution control policy system}

Before studying the specific agricultural non-point source pollution causes and establishing a proper pollution control policy model for China, it is necessary to study experiences of pollution control from other countries.

\subsection{International experiences of agricultural non-point source pollution control}

The situation of agricultural investment of Europe and Japan is similar with China, followed by the United States and Australia. So the paper will provide some examples of agricultural non-point source pollution control experience of Europe and Japan.

3.1.1 The experience of reasonable application of pesticides and fertilizers The European Union controls the application of fertilizer and pesticide through the market and rural development. The EU started the rural development plan to develop organic agriculture and make reasonable agricultural measurement system that is environmental safety in 1993. The EU established strict standard according to the amount and time of application of chemical fertilizer and organic fertilizer, quality of organic fertilizer and discharging and treatment of organic waste. At present, the EU is about to start work on the national discharge standard and the reduction of ammonia volatilization.

The EU implements control measures of non-point source pollution mainly in farms. The main measures include: the farmer must follow the ban period of fertilizers (farms cannot apply liquid manure from October to next February) and the requirement of slope (contour lines cropping); the implementation of the organic agriculture or the comprehensive agricultural fertilization management (keep a reasonable ratio of $\mathrm{N}$ to $\mathrm{P}$, balanced fertilization, maintain vegetation in the rain season); the restriction of rotation water source protection areas or water conservation areas; to control the density of livestock and to build buffers (livestock farms must have sufficient areas of farmland for all solid and liquid wastes, 1.5 livestock units per hectare of arable land); to improve the capacity of organic manure storage (expand the waste storage tank of livestock, its capacity needs to be capable of storing liquid waste discharged within 6 months, the requirements for sealing is not generated runoff), control of the amount of organic manure fertilizers (less than $170 \mathrm{~kg} \mathrm{~N} / \mathrm{ha}$ ).

Canadian legislation allows the application of fertilizer should not exceed 100 to 150 $\mathrm{kg} \mathrm{N} /$ ha every year. Holland legislation allows the manure quota from 1995 to 1999 
for food crops and grassland are $55 \mathrm{~kg} \mathrm{P} /$ ha and $76 \mathrm{~kg} \mathrm{P} /$ ha. The manure quota for food crops and grassland is $31-33 \mathrm{~kg} \mathrm{P} /$ ha and $48 \mathrm{~kg} \mathrm{P} /$ ha after 2000 .

Pesticide pollution control measures of EU include two aspects. On the one hand, the products are authorized by a comprehensive evaluation for high quality pesticide production. On the other hand, imparting the best operational measures to farmers through training and promoting the use of spraying machine that is suitable for farmers through the inspection certificate and technology. At the same time, the EU established the double evaluation system in EU Member States. The EU evaluated the active ingredient of pesticides and released a list of products. Each member gives evaluation and authorization to the product contains the active ingredient. The EU requires farmers to use pesticides in accordance with the instructions on the label and specially formulates the standard amount of pesticide residues in commodities and ensures the safe use of pesticides.

\subsubsection{Compulsory and voluntary method}

Many developing countries find it is difficult to monitor the implementation of control measures. So the point on the control of agricultural non-point source pollution is the use of voluntary method or combination of economic incentives (payments for environmental services) or punishment (the illegal discharge of sewage fine). Although many countries have formulated good agricultural measures and guidelines for environmental safety, it still needs to be promoted to take the corresponding rewards and punishment methods (such as pollution taxes).

\subsubsection{Application of economic measures}

The EU is the first to adopt the pollution tax for controlling the chemical fertilizer and pesticide pollution. There are two features of the pollution tax: one is that the EU farmers reduce the amount of chemical fertilizers and pesticides before high rates (50$100 \%$ ). Another is the pollution tax is not easy to operate. Austria was in an implementation of the pollution tax for 4 years before they give up. Denmark change to a general method, namely farmers make fertilizer management plan to eliminate the pollution tax.

\subsection{Evaluation of non-point source pollution control policy}

When many scholars focus on the investment in non-point source pollution policy design, at the same time, there are also many scholars began to concern the policy evaluation problem. Table 1 lists and describes some policy evaluation conclusions. Evaluating alternative policy tools will help decision makers identify which tool is the best suitable for special water quality problems. Sometimes, the most suitable tool for correcting policy tools is the other policy tools. 
Table 1 Policy evaluation conclusion

\begin{tabular}{|l|l|l|}
\hline \multicolumn{1}{|c|}{$\begin{array}{c}\text { Author and } \\
\text { year }\end{array}$} & Evaluation object \\
\hline $\begin{array}{l}\text { Shortle and } \\
\text { Dunn (1986) }\end{array}$ & $\begin{array}{l}\text { Incentive input, } \\
\text { Standard input }\end{array}$ & $\begin{array}{l}\text { Ensured proper incentive input is better } \\
\text { than standard input, but this is not suitable } \\
\text { for multi-farm area. Because transaction } \\
\text { cost should be considered in those places. }\end{array}$ \\
\hline $\begin{array}{l}\text { Cocharda } \\
\text { et.al (2002) }\end{array}$ & $\begin{array}{l}\text { Input tax, } \\
\text { environmental } \\
\text { legislation, fine }\end{array}$ & $\begin{array}{l}\text { The efficiency and reliability of input tax } \\
\text { and fine is good, both of them increase } \\
\text { social welfare based on the present } \\
\text { situation. On the contrary, environmental } \\
\text { legislation reduces social welfare, and its } \\
\text { effect is very unreliable. }\end{array}$ \\
\hline $\begin{array}{l}\text { Abler and } \\
\text { shortle } \\
\text { (1991) }\end{array}$ & $\begin{array}{l}\text { All kinds of } \\
\text { policy tools } \\
\text { (education, } \\
\text { subsidy, input tax } \\
\text { etc.) }\end{array}$ & $\begin{array}{l}\text { Cannot make sure which one is the best, } \\
\text { each one has its advantages and } \\
\text { disadvantages. The application of the } \\
\text { policy should rely on the characteristics of } \\
\text { the area. }\end{array}$ \\
\hline $\begin{array}{l}\text { Conant et.al } \\
\text { (1993) }\end{array}$ & $\begin{array}{l}\text { They four research } \\
\text { tools. The four } \\
\text { policy tools are: } \\
\text { standard of } \\
\text { pesticide } \\
\text { management, } \\
\text { input tax of N } \\
\text { fertilizer and } \\
\text { pesticide, } \\
\text { technical support } \\
\text { of comprehensive } \\
\text { crop } \\
\text { management, } \\
\text { education. }\end{array}$ & $\begin{array}{l}\text { 1) The benefit of water quality is the most } \\
\text { through tax. 2) The water quality can be } \\
\text { improved significantly under the } \\
\text { circumstance of no loss of profit rate. Even } \\
\text { sometimes, the water quality and profit can } \\
\text { be both improved with low implementing } \\
\text { cost. 3) When the farmer applied a new } \\
\text { policy, the change caused by the policy is } \\
\text { unsure. However, the change can only } \\
\text { affect the water quality and profit rate and } \\
\text { policy. The influence on water quality and } \\
\text { profit rate is different in different areas. }\end{array}$ \\
\hline
\end{tabular}

The function and effect of each policy are different. The implementation of tax policy is the most common. Its function is to 'block', and its effect is more outstanding. Sewage charges are suitable for the control of livestock and rural village pollution. Input tax and products use tax can control excessive application of chemical fertilizer and pesticide of farmland. The function of subsidies is to 'dredge'. Although its effect 
is not ideal and fast as tax means, the combination of taxes and subsidies to reward simultaneously can decrease the non-point source pollution.

\subsection{The main causes of ANPSP in China}

First, it is necessary to study the factors that lead to ANSPS in China before giving a proper ANPSP control policy system for China, thus providing some effective and detailed measures. The specific reasons are as follows:

(1) The pressure of food security

In the past 50 years, the grain output of China increased a lot, thanks to innovation and technology progress to a great extent. A very important reason is the modern agricultural investment, especially increased fertilizer inputs. Statistics shows that, per capita grain production of China in 1961 is only nearly $60 \%$ of the world's average level. However, by 2011, in addition to milk, per capita output of grain and meat is more than the world's average levels (Chinese Department of Statistics, 2011).

Historical data show that the growth of grain production is positively related to the application rate of fertilizer. But at the same time, agricultural non-point source pollution increases rapidly (Jian 1999). Therefore, in order to guarantee the grain yield increased continuously, the high level of investment in agriculture (especially fertilizer input) will be inevitable. If there are no effective control measures, agricultural nonpoint source pollution will be more serious.

In addition, from the aspect of the international environment, China's accession to the World Trade Organization will help Chinese agriculture to go to the world, while increasing the pressure on a rural environment. According to the forecasting research, if there are no effective control systems and the farmers cannot get appropriate technology promotion service, the application amount of chemical fertilizer and pesticide will also increase along with the development of free trade (Shuilong 1998). This is mainly because of the impact on trade liberalization of agricultural production input factors and the prices of agricultural products, thus affecting crop production structure (size of structure or crops) as well as the unit area of fertilizer and pesticide input. The relatively low international market price of chemical fertilizer and pesticide itself would induce farmers to fertilize. High production expansion of vegetable, flower and fruit will further promote excessive fertilizer and pesticide application, thus increasing the pressure on the environment and the difficulty of non-point source pollution control.

(2) The rapid development of vegetable production

Vegetable production has become the most internationally competitive industries of agricultural production in China. Many provinces have reached the goal that the output 
of vegetable is more than half of the total agricultural output under the condition that the planting area of vegetable is only $20 \%$ of the total agricultural area. In 2011, the vegetable and melon planting area of China is more than 19700000 hectares and the total output is about 601000000 tons, of which there are more than 160 counties' (including county-level cities and districts) vegetable planting area is more than 20000 hectares. But because of the lack of reasonable technical support, excessive fertilizer investment of vegetable production is a very common phenomenon. Since the 1990s', the problem of excessive fertilizer investment of intensive vegetable producing areas such as Liaoning, Shandong, Heilongjiang, Jiangsu, Shanxi, Hebei, Beijing, Hunan, Tianjin, Ningxia is reported more and more (Lipin C et. al, 2011).

The problem of intensive vegetable production is in three aspects. The first is the excess of water fertilizer inputs, especially the excessive nitrogen input. In 2000, in addition to Inner Mongolia, the nitrogen fertilizer of vegetables in other provinces is more than $200 \mathrm{~kg} /$ ha. The $\mathrm{N}$ fertilizer input in Shandong province is up to $735 \mathrm{~kg} / \mathrm{ha}$. In the survey of 198 households in Shandong Huimin County in 2010, the average nitrogen application rate of open field in a single season was $627 \mathrm{~kg} \mathrm{~N} /$ ha and the rate of greenhouse vegetables was $1382 \mathrm{~kg} /$ ha, nitrogen utilization rate is lower than $10 \%$ (Hesheng, et.cl 2011). Compared with the proper average ratio of vegetables to absorb nutrients ( $\left.\mathrm{N}: \mathrm{P}_{2} \mathrm{O}_{5}: \mathrm{K}_{2} \mathrm{O}=1: 0.36-0.40: 1.25-1.43\right)$, the ratio of chemical fertilizer of vegetables is not reasonable. Many provinces use the fertilizer of high phosphorus and low potassium, thus leading the vegetable production and economic benefit reduction and the nutrient use efficiency decrease.

Nutrient input of cucumber and tomato in Shouguang County of Shandong province is $2063.9 \mathrm{~kg} \mathrm{~N} / \mathrm{ha}, 2532.6 \mathrm{Kg} \mathrm{P}_{2} \mathrm{O}_{5} / \mathrm{ha}$ and $1585.3 \mathrm{~kg} \mathrm{~K}_{2} \mathrm{O} / \mathrm{ha}$. Organic manure nutrients are respectively $1006.9 \mathrm{~kg} \mathrm{~N} / \mathrm{ha}, 898.7 \mathrm{~kg} \mathrm{P}_{2} \mathrm{O}_{5} / \mathrm{ha}$ and $807.1 \mathrm{~kg} \mathrm{~K} 2 \mathrm{O} / \mathrm{ha}$. Nutrient input is 2-6 times of the required amount of vegetables. In 2010, the whole fertilizer loss amount of Shandong province is estimated to be 117952 tons N, 151696 tons $\mathrm{P}_{2} \mathrm{O}_{5}$ and 65440 tons of $\mathrm{K}_{2} \mathrm{O}$ (Wenying and Zhiwei, 2011).

The second is the excessive application of nitrogen, which not only causes vegetables nitrate enrichment, also serious vegetable plant diseases and the increase of the use in pesticides and residues. Also, excessive application of $\mathrm{N}$ has a great negative impact on the quality of vegetables. Moreover, excessive application of chemical fertilizer destroys the good structure of vegetable soil and causes serious pollution groundwater environment. In recent years, it becomes a potential threat to the eutrophication of the water body. The research in intensive vegetable production areas found that the $\mathrm{N}$ fertilizer of vegetable brings more than $200 \mathrm{~kg} \mathrm{~N} /$ ha to groundwater each year (Ruitang and Jianzhou, 2012). 
Third, the soil fertility continues to decline caused by excessive use of chemical fertilizer for vegetable. Therefore, the farmers are dependent on the increased application of chemical fertilizer to maintain the current production capacity, thus forming a bad circulation and leading to serious deterioration of the ecological environment of soil in the vegetable field.

\section{(3) Imbalance of farmland nutrient cycling}

The proportion of organic and chemical fertilizer is changing greatly in China and the proportion of organic fertilizer is declining. Before the 1970's, the farmland nutrient supply mainly depends on the organic fertilizer. But the use of traditional farm manure decreases with the increased level of economic development and the opportunity cost of labor. The use of chemical nitrogen fertilizer exceeds the use of organic nitrogen fertilizer in the mid 1970's. The situation of organic phosphorus fertilizer is same with organic nitrogen fertilizer. However, potassium fertilizers of the farmland still rely on organic fertilizers.

Due to the unreasonable use of fertilizer, fertilizer use efficiency of nitrogen is very low. The efficient rate of nitrogen fertilizer is only $30 \%-35 \%$. The unreasonable application of chemical fertilizer not only leads to the decrease of the yield and quality, also the decreases economic benefit of fertilizer and serious non-point source pollution.

From the aspect of China's nutrient balance of farmland system, since the nineteen seventies, most areas of China, especially the large number of surplus nitrogen balance of farmland in the eastern area. Phosphorus also has turned from a deficit to a small surplus (partial vegetable areas' phosphorus appears a large number of surpluses). However, potassium of the farmland still is in deficit condition. Nitrogen surplus (before loss) increased at a faster rate before 1998. It is in a steady growth in recent year and expected to reach 22.4 million tons in 2015 (Environmental Protection Administration of China, 2010.).

The evaluation on nitrogen balance of nearly 5 years shows that the amount of chemical fertilizer is large, and the nitrogen surplus brings risks to the environment in some of China's economically developed provinces and cities, such as Shanghai, Jiangsu, Guangdong, Fujian, Beijing, Shandong and Henan. In the northern and western region of China, such as Xinjiang, Qinghai, Inner Mongolia, Heilongjiang, Guangxi Province, the farmland fertilizer rate is relatively low, and the risk of nitrogen surplus is also low.

(4) The rapid development of large-scale breeding of livestock and the low treatment rate of organic waste

The livestock and poultry breeding develop rapidly in China. In 2009, the amount of pigs was 0.56 billion, and the growth rate is $8 \%$. The amount of poultry is 4.73 billion 
and the growth rate is $13.4 \%$ (Chinese Department of Statistics, 2009). The amount of feces of livestock and poultry is 2.7 billion tons. In 2009, the feces of livestock and poultry production were 4.1 times of industrial organic pollutants. In 2015, this will be expected to reach 6 billion tons (China Environmental Protection Committee, 2009).

In recent years, the use of organic fertilizer of China has been ignored. Large amounts of organic fertilizer especially human and animal manure are turning into a source of pollution from the nutrient source. Agricultural utilization ratio of nutrient resources of organic fertilizer depends on the collection rate of organic fertilizer and loss rate in the process of storage. Large-scale breeding of livestock establishes the promotion of economic development, while bringing the difficulty to the treatment of livestock excrement. Large amount of livestock feces directly flow into surface water and cause Lake Eutrophication. In the developed rural area, due to the rapid development of livestock and poultry industry and the increased population, farmland organic nutrients serious overload. The lack of sewage pipes and sewage centralized treatment system is causing no restriction of the field emission and the loss of ecological function of the soil.

At present, the problem is China is the lack of environmental assessment regulations of animal manure treatment. More than $90 \%$ of the national livestock and poultry farms do not have sewage treatment systems and equipment. At the same time, the processing system of livestock manure is separated from the field, and most of the livestock manure is wasted as a pollution rather than fertilizer, so the organic nutrients are hard to reuse through farmland. In 2011, China's rates of using beef cattle, swine, poultry and dairy cattle manure to produce organic fertilizer were $44 \%, 43 \%, 10 \%$ and $3 \%$. $\mathrm{N}$ and $\mathrm{P}$ emission rate of livestock and poultry manure in Tibet, Qinghai and the coastal provinces are higher, and the trend is increasing (China Environmental Protection Committee, 2011).

(5) The lack of agricultural technology promotion system

The study of how to reform agricultural technology promotion system to adapt to the market economy conditions began in the mid 1990's. However, some problems of the system are still not resolved and cannot meet the needs of agricultural technology promotion work under the condition of the market economy. To sum up, the disadvantages of the agricultural technology promotion system of China mainly exist in the following four aspects: 1) the input and scale of the agricultural technology promotion system are not much. In 1999, investment of agricultural technology promotion accounted for only $0.49 \%$ of the agricultural GDP of China. The input level is only equivalent to the average level of low income countries in 1980's and far below the average level of industrial nations (0.62\%) of year1980 (Yinxu 2002). 2) the use of the investment funds is not reasonable, and most of the investment is mainly used for 
wages (80\%). As a result, there are few promotion funds for grass-roots agricultural promotion work. In addition, because the local financial stress, even there are funds for the grass-roots level government, a large part of the promotion investment is often used for other purposes by the local government. The quality of promotion staff is low. The main workers have no qualified education and training. Investigation shows, only $10 \%$ of the system workers have a bachelor's degree in 2009 , and $46 \%$ of the staff do not receive any training (Chinese Department of Statistics, 2009). At the same time, the trained workers also do not update the knowledge and skills and cannot meet the demand of the promotion system. Due to the lack of sufficient operating funds, the stuff of local technology promotion system has to do business to make money for promotion actives. But the major business activities include selling fertilizers and pesticides. Because of its benefits conflict with the promotion goal, the system lacks an incentive mechanism to encourage them to guide farmers to reduce pesticide and fertilizer. 3) The current existing technical system lacks efficient fertilization technology. Currently, the technical system of China lacks technology study of fertilizer on circulation and optimizing management of nutrients. The existing fertilization technology is hard for farmers to apply, while is not suitable to the situations of different regions. A lot of fertilizer control measures also are not applied from the source of ASPSP. 4) The current system mostly focuses on field ANSPS control and ignores the ANPSP management of water. The ANPSP control technical system of China is lacking water pollution control and is especially lacking management based on using a single river as a unit. There is no decentralized sewage treatment system in the rural area and aquaculture wastewater reuse in the culture area.

(6) The lack of subsidy system for ANPSP control

At present, agricultural non-point source pollution control is a serious lack of subsidy policy in China. There are a lot of difficulties in the process of forming subsidy policy. The difficulties come from unreasonable development strategy, planning and policy management in the process of the rural area shifting into the urban area. For a long time, China has established the implementation of two dimensions in urban and rural areas. Pollution control investment is almost entirely invested in industry and city, so rural and agricultural pollution control and environmental management is seriously lack of funds.

Agricultural cleaner production needs to pay a relatively high cost. If the realizing cycle has no direct economic benefit or economic benefit of longer, there are different degrees of reducing the desire of farmers choosing low carbon technology. Because of the absence of agricultural environment subsidies as voluntary promise for farmers, farmers' selections on the ecological and sustainable agriculture mode are not being stimulated. Because the agricultural environment subsidies amount and the environmental protection investment are closely related, the farmers can consciously 
put the environmental protection concept in agricultural production driven by the benefits and achieve environmental protection and cleaning production management. This guide is indispensable for agricultural, environmental protection.

(7) Other reasons that lead to excessive fertilization or unreasonable fertilization are the rapid change of market economic environment. Due to the increase of nonagricultural employment opportunities, many farmers go out to work. This has been a big influence on the industrial structure and production inputs. On the other hand, due to the increasing income of farmers, they can have more money to buy chemical fertilizers and pesticides.

The selection of human behavior depends largely on the policy guidance. However, China's agricultural policy and environmental management are unrelated for a long time. Especially the lack of laws and regulations to supervise agricultural non-point source pollution control is an important reason that agricultural non-point source pollution have existed and aggravated for a long time in China. In order to control the growing of agricultural non-point source pollution effectively; speed up the formulation of environmental legislation; at the same time, the formulation and implementation of flexible and effective management policies in different regions and different types of agricultural non-point source pollution based on economic incentive principle is necessary.

\subsection{The frame of agricultural non-point source pollution control policy system in China}

In view of the above problems, China's agricultural policy and environmental policy should be adjusted: 1) at present China has solved the problem of food security. Agricultural policy is not only increasing the yield, but not conducive to the protection of the ecological environment conditions. Especially in the important water environmental protection zone, the government should limit farmers' unreasonable production; reduce production strength; and guide farmers to engage in ecological agricultural activities that can obtain economic benefit, while doing no harm to the environment. 2) To strengthen the legislation and to design the guiding and incentive environmental policy that is matching regulatory policy, thus making the farmer consciously give up the production behavior that is not conducive to the environment and saving policy implementation costs. In which the government's task is to improve the level of environmental science and technology and the means of accessing information, thus making the farmers quickly obtain the necessary environmental information, and environmental protection technology and creating the conditions for the supervising the public; to strengthen environmental protection education and to improve farmers' environmental awareness; to allocate the initial environmental rights 
fairly and effectively; to formulate relevant incentive system, so that the farmers and enterprises can participate in the environmental-friendly activities and obtain benefits.

Based on the situation and the basic theory of environment policy, environmental economics, environmental management science, agricultural economics, combined with China's natural, social and economic conditions and the causes and characteristics of agricultural non-point source pollution, the agricultural non-point source pollution control policy system in this thesis will have four aspects: 1) Governance policy based on the farming management. 2) Environmental legislation based on the tax of restriction and constraint function. 3) Technical system based on the improvement of fertilization and pesticides. 4) Subsidies, compensation and other preferential policies based on guiding and encouraging function. All of these aspects make the policy model in this thesis and explain that where the model comes. As showed in Figure 2. More details will be explained in the following contents.

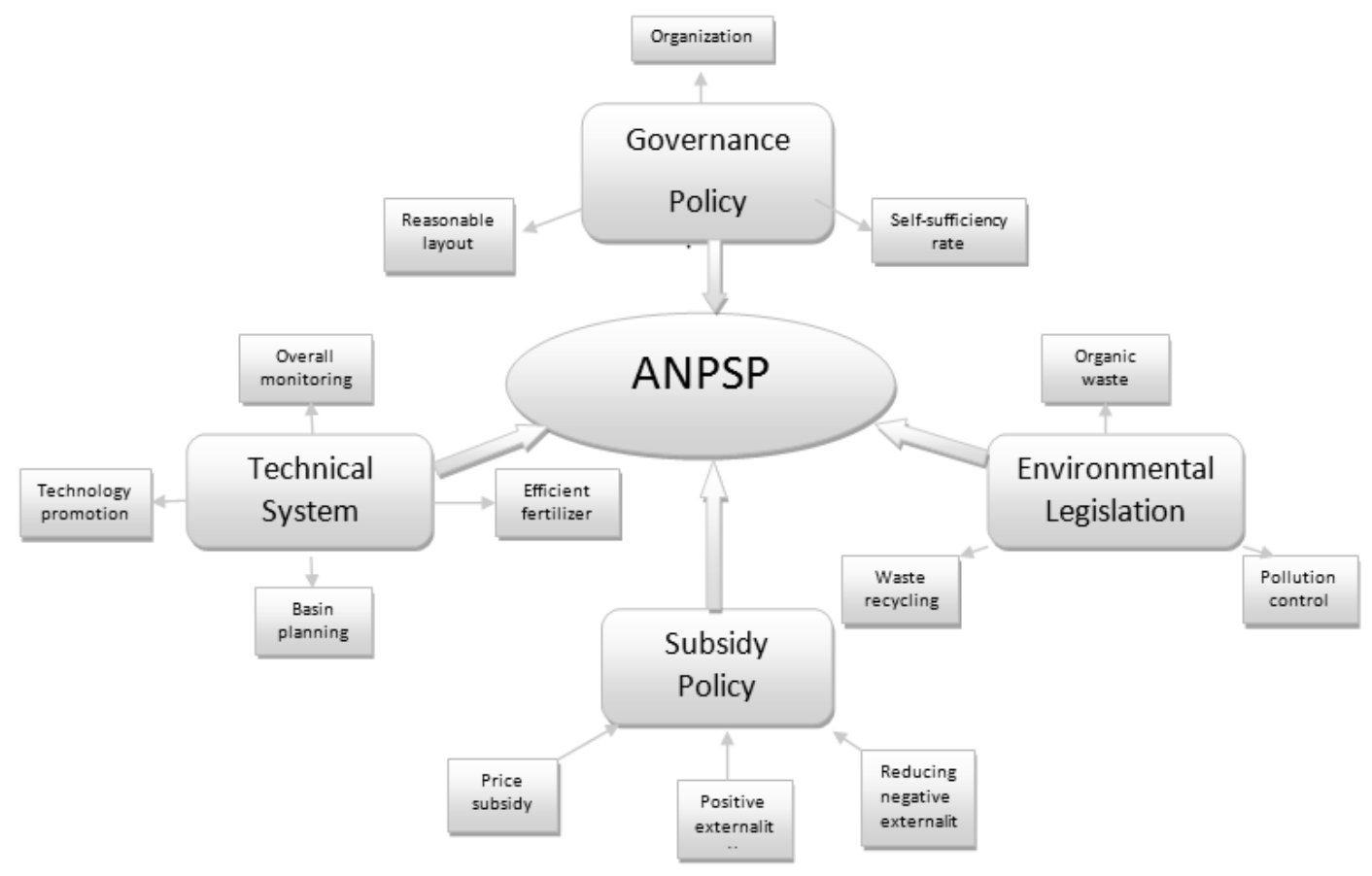

Figure 2 Policy Model for the control of non-point source pollution 


\subsubsection{Governance Policy}

After studying the causes of ANPSP of China, we know that the excessive grain and vegetable production are causing serious pollution problems. Therefore, the governance policy is made to solve pollution problems brought by excessive food production. The goal of governance policy is to reduce the ANPSP through decreasing the food production properly based on the premise of maintaining sufficient food for people; reasonable layout and construction of grain base; and the construction of professional technology organization for farmers. We all know the fact that the water resource and arable land are reducing year by year. The situation of arable land protection in China is very serious. The decreasing trend of arable land has not changed. From 1958 to 2011, the national reduction of arable land is 40733000 hectares and an annual reduction is 1405000 hectare (Chinese Ministry of Land Resources, 2011). Therefore, decreasing food production is not only reducing the application of fertilizer and pesticide, also saving the water resource and arable land. Possible measures for China to control the pollution of fertilizer and pesticide brought by excessive production of food are as follows:

(1) Decrease food production based on maintaining proper self-sufficiency rate of grain and food security

The total grain output and the per capita consumption of China are 0.512 billion tons and $412 \mathrm{~kg}$ in 1998 (the highest yield year). In 2003, they were 0.43 billion and $330 \mathrm{~kg}$ (China Grain Bureau, 2003). Estimated by 2030, the population of China will reach 1.6 billion, calculated according to $400 \mathrm{~kg}$ per capita and the total output of grain should reach 0.64 billion tons (the Statistical yearbook of China, 2010). It brings a lot of pressure on the demands of increasing of grain yield when considering the areas of arable land will inevitably reduce.

Ensuring national basic food security is a long-term strategic goal of China. China has made great achievements on increasing food production and ensuring food security in recent 50 years. However, many phenomena have shown that these achievements are at the expense of destroying the environment to some extent. Now the government has to face the complex problems that are far more than the simple pursuit of food safety. In the new stage of economic development, the government should take into account the food security and sustainable development. Therefore, it needs to rethink and make food self-sufficiency rate properly. Appropriately increasing the proportion of food imports can reduce the pressure of fertilizers on the environment. The thesis suggested that because of the wealth of China's foreign exchange reserves, appropriately reduce China's grain self-sufficiency rate to $90 \%$ is desirable (defines food security as ration, feed grain except). At the same time, the government should pay more attention to improve agricultural production, especially strengthening the research of agricultural science and technology. 
(2) Reasonable layout and construction of grain base

China is a large country with billions of people. So except for decreasing grain production to reduce ANPSP, at the same time, China should fully use its limited arable lands. Therefore, optimally using the lands is urgently necessary. The paper suggests adjusting the regional grain base construction planning and the industrial structure of agriculture at the macroscopic level. Since the environmental pressure is larger in the high yield food base area, so the point is to ensure high and stable yield in the area, while reducing irrationally excessive use of fertilizers and improving the economic benefits of planting grain. In addition to continue developing the production potential of black soil region in the north east of China, it needs to evaluate the feasibility of a strategic shift of key areas of grain production. The paper suggests transferring the key areas from the high yield region with serious non-point source pollution problems (Tai Lake basin) to the middle yield area. Compared with the low yield area, the restriction of the middle yield area is less, and potential of yield is higher; also the transformation cost is low. So it is suitable to regard middle yield areas as a key area for increasing the grain production of China. The fertility and productivity of middle yield area can be greatly improved with irrigation and fertilization technology in a relatively short period time. Also, pressure of the grain productive area can be reduced.

(3) To strengthen the construction of professional technology organization for farmers

For those limited arable lands, application of fertilizer and pesticide is still needed. Therefore, how fertilizer and pesticide properly applied is a problem to resolve. International experience shows that the farmer associations or cooperatives can effectively organize farmers and farmers market sales, give technical training and guide farmers to increase public awareness of environmental protection. In addition, encouraging farmers apply environmentally friendly farming methods from the public credibility. Japan sets up the honorary title (Eco-farmer) in the development of sustainable agriculture to encourage farmers to protect the environment. Britain stipulates for registering every 1-2 year in the construction of an organic farm.

No matter from the general technology promotion, market activity or environmental protection, there is an urgent need to establish farmers' professional technical organizations in China. Also, in this way, the problem of imbalance of farmland nutrient cycling we mentioned before can be improved with the establishment of the professional technology organization.

Although the government is promoting the establishment of such an organization in many aspects, a recent study shows that: there are only $2 \%$ of farmers participated in the farmers' professional technical organizations (Dancheng and Wenfang 2009). On 
the other hand, due to the lack of legal status and perfect management system, the role of farmers' professional technical organizations is restricted.

In order to ensure the healthy development of farmers' professional technical organizations, the paper advises to take the following suggestions: 1) the transformation of government functions is needed, and the government needs to provide support to the farmers' professional technical organizations in terms of credit, training, information exchange. 2) The establishment of relevant laws and regulations for the management of farmers' professional organization. 3) To create conditions to promote the establishment of farmers' professional technology organization and the effective operation. 4) To allow farmers' professional technology organizations to engage in financial business or credit functions for helping farmers to get loans.

In China's economically developed eastern coastal areas, the thesis suggests carrying out the land scale management; developing agriculture planting industry specialist; emphasizing the application of the rational application of fertilizer and fertilizer; reducing fertilizer costs, and improving the efficiency of plant industry.

\subsubsection{Environmental legislation}

Policy designers often take environmental tax as the most useful policy tool for the environmental management and tend to regard it as a reference for other tools. The design of an environment tax should be consistent with the basic principle of tax revenue target and the modern tax system. These principles include (The Organization for economic cooperation and development, 1996b): 1) the tax neutrality. Tax neutrality refers to the design of the tax system can only be affected by the tax factors, rather than action or reaction of economic departments. The design of an environment tax is to guide the polluters to reduce emissions and shift to the environmentally friendly way of lifestyle. Tax neutrality only exists in the absence of externalities and other market failures. The reason is that an environmental tax is to correct the market failure and it is not conflicting with the overall revenue neutral standard. 2) Fairness. The environmental tax has a remarkable influence on the distribution of the family as well as the production department. This requires the government to establish a compensation mechanism in the design of policy in order to emphasize the tax equity is given special attention, so as to avoid obvious mistakes brought by the environment tax. 3) Special use. The advantage of the special use of environmental tax and charge is to promote a new tax, which makes the link between tax and environmental objectives clearer than general tax. However, special use may weaken the stimulation effect of tax policy, therefore, if the design of environmental tax can generate enough stimuli to change the farmer's behavior, then there is no need for special use, the fee income can be incorporated into the general budget. The possible regulations for China are as follows: 
(1) The regulation for controlling organic waste emissions

In the progress of development of Chinese agriculture, the future adjustment of agricultural structure should transfer from the land intensive (such as food production) to the labor intensive (such as gardening and farming and processing). Livestock industry is the development trend of the future of agriculture. Treatment of livestock pollutant is an important aspect of non-point source pollution control. Therefore, the goal of establishing organic waste emission control regulations is to solve the problem of the rapid development of large-scale breeding of livestock but low treatment rate of organic waste.

In the aspect of control of waste pollution, the government should firstly develop high quality and high yield agriculture that is coordinated with environmental protection. The government should vigorously develop pollution-free agriculture and appropriately develop "green food" production to promote the use of organic fertilizer. The government should fully implement the green agricultural products industry standard provided by the Ministry of agriculture. The government should control and improve the production process of organic food and reduce pesticide and heavy metal pollution bring by organic fertilizer (such as some livestock manure).

The paper suggests adopting legislative experience of EU and enacting policies and regulations relating to the use of commercial organic fertilizer production. The environmental quality standards of the livestock industry should be set up through the rural development planning (including the scale breeding of livestock density, manure storage and processing capacity, organic waste, buffers etc.). Increasing the harmless disposal rate and recycling rate of livestock's feces and restricting random feces of human and animal.

(2) The regulation for promoting the development of organic waste recycling

For the organic waste that has already existed, the government should establish regulations to recycle them. However, the use of organic fertilizer of China in recent years has been ignored. Large amounts of organic fertilizer especially human and animal manure turned into a source of pollution from the nutrient source. China produces billion tons of agricultural organic waste every year, due to pollution accidents and incidents increasing year by year, people gradually paid attention to it. Agricultural organic waste contains huge resources. For example, if use crop straw as fertilizer, it can provide nitrogen $(\mathrm{N})$, potassium $(\mathrm{K})$ and phosphorus $(\mathrm{P})$ elements to the soil (Zhenyun, et.al 2004).

The paper suggests promoting the development of China's commercial industry of organic fertilizer and formulating national standards and relevant fertilizer quality standards. It can encourage studying the technology and production method of 
development of organic fertilizer form policy. It is important to reduce nutrient loss of production and storage of organic fertilizer resources. The government should take efforts to improve the agricultural utilization ratio.

The government should establish regulations for organic fertilizer. The paper suggests setting up a standard for organic fertilizer use, using time and method of application according to the regional climate, soil, crop conditions (including the development of a balanced rate of organic manure and inorganic manure). Reducing non-point source pollution caused by the process of application. At the same time, the government should promote the development of rural environmental planning and carry out a comprehensive utilization of straw combine with the biogas project and decrease the environmental impact caused by straw burning.

(3) The regulation for pesticide pollution control

China is a big country of producing and using pesticides. Pesticide application area is more than $2.8 \times 108 \mathrm{hm}^{2}$ and the average amount of pesticides is $(50-60) \times 107 \mathrm{~kg}$. Pesticide production is mainly concentrated in Jiangsu, Zhejiang, Tianjin, and Shandong, etc. But the large amounts of use are in Shanghai, Zhejiang, Jiangsu, Shandong and Guangdong. At present, there are farmlands of $870000-1070000 \mathrm{hm}^{2}$ polluted by pesticide pollution. In this situation, the government's control pesticide pollution through regulation measure is needed urgently except for the governance policy we mentioned.

The paper suggests establishing a technical standard system of cleaner production technology in the producing area as Jiangsu, Zhejiang and adopting standardized production to guide and help the farmers applying scientific fertilization and using the drug safely. At the same time, the government should support the good agricultural products brand and improve the inspection and testing system. The expansion of supervision and control of the agricultural product quality is needed. Increasing the ratio of high quality and safety standards of agricultural products is also needed.

The government should strengthen pesticide pollution control and strict pesticide registration and management while taking active measures to eliminate a number of highly toxic pesticides and persistent pesticide. The paper suggests establishing development of new pesticides that are environment friendly (high efficiency, low toxicity and low residue pesticides) to improve the technical level and quality of pesticides.

In the use of pesticides, the pesticide formulation should use national standard and adhere to the principle of prevention first and comprehensive prevention. The government should establish the pest forecasting information system and promote the integrated control technology and biological technology for disease of plant and insect. 
The government should vigorously promote the bio-pesticide and reduce the use of chemical pesticides, while strengthening basic research method of new pesticide spraying appliance and improving pesticide application technology.

Reconstruction of the rural pesticides professional and technical services team is needed. The government should strengthen the technical training and technical guidance for the safe use of pesticides while improving safety awareness of using a pesticide.

\subsubsection{Technical system}

Technical System disadvantages of China mainly have following problems: 1) the input of agricultural technology system is too low. 2) The use of investment funds is not reasonable, and promotion personnel quality is low. Therefore, this thesis will provide some measures for these issues.

(1) The overall monitoring of quality and environmental capacity of farmland

For low input and scale problem mentioned at the beginning of this chapter, the paper suggests that the government should establish farmland environmental capacity standard for residual pesticide and nitrate based on the quality of relevant soil environment and safety of agricultural product testing standards. At the same time, the farmland environment safety survey should be taken timely. Recognition planning and management of the high risk area of non-point source pollution are needed.

In the aspect of monitoring, the local governments should work together with the State Environmental Protection Administration, the Ministry of agriculture and the Chinese Academy of Sciences to establish a national farmland ecological environment monitoring network and environmental monitoring information system. At the same time, the government should set up a supervision system for monitoring the ecological environment and the quality of agricultural products.

(2) The efficient technology promotion system

For the problem of unreasonable use of the investment fund and low quality personnel, this paper gives some recommendations for Agricultural Technology Promotion Services, and they are as follows: 1) To focus on the fertilizer and pesticide management and technology promotion, while reforming the system and reducing redundant personnel to improve the efficiency, 2) the agricultural technology promotion and commercial activities (such as the sales of chemical fertilizers and pesticides) should be strictly separated; 3 ) increase the investment of promotion and improve the functions of the promotion system; 4 ) to introduce a participatory idea and let the farmers have opportunities and channels to reflect their problems while allowing farmers to participate in the promotion of new fertilizer and saving the 
technical trainings actively, so that they can fully understand the relationship between their behaviors of application of fertilizer and pesticide and environmental protection, 5 ) to train the staff in the system and strengthen the updating of the knowledge of environmental protection technology.

(3) The efficient fertilization technology

The problem that the current technical system lacking in efficient fertilization technology we mentioned before. This paper suggests that the government should make the sustainable development of agriculture as a goal and strengthen the basic research of the management of cycling and optimization of nutrient in the agricultural ecosystem according to the general principles of "high yield, high quality, high efficiency" and "low consumption, no pollution". The government should widen thoughts and develop a simple, suitable new fertilization technology for different regional conditions, while strengthen the routine assembly of fertilization technology. The government should control the non-point source pollution from the source of nitrogen and phosphorus fertilizer.

First of all, the government should determine the division of fertilizers of main crops in China (wheat, maize and rice) according to the appropriate amount of nitrogen fertilizer in different regions. The methods include semi-quantitative determination method and average suitable amount of nitrogen application method based on the forecast of the amount of soil nitrogen supply. At the regional scale, the government should make the village as a unit to establish farmland precise fertilization decisionmaking system. The government should apply balanced fertilization, soil testing, and precision crop fertilization based on soil nutrient status and crop growth model.

Secondly, the government should apply water and fertilizer management measures and avoid large early application of nitrogen fertilizer in crop growth. The fertilizer should be mainly applied in a vigorous growth period in order to reduce the loss of nitrogen fertilizer application.

In addition to the application of slow-release, research and development of new highly efficient fertilizer should be strengthened in order to reduce nitrogen loss from farmland.

(4)The comprehensive river basin planning and watershed management

The thesis mentioned at the beginning of this chapter that the current system mostly focuses on field ANSPS control and ignores the ANPSP management of water pollution. For this problem, the paper suggests that the government should take the watershed as a unit and integrate planning and management in the non-point source pollution control of China. The government should start construction of farmland ecological interception system to reduce emissions of farmland based on the control of 
$\mathrm{P}$ and $\mathrm{N}$. The construction of rural decentralized sewage treatment system is also needed. The government should promote the development of regional river management, the construction of ecological river and development of aquaculture wastewater recycling in the culture area.

Farmland ecological interception system takes small watershed as a unit. On one hand, the system makes adjustment for planting structure and adopts interplanting intercropping to control and reduce surface runoff in vegetable land. On the other hand, the system establishes a nutrient loss interception and transforms the traditional soil ditch. At the same time, the system also establishes an ecological interception ditch and reduces the concentration of farmland drainage before flowing into the river to protect the water environment. In the high risk of contamination zone (vegetables or flowers around), the system establishes physical and biological isolation belt to prevent emissions of $\mathrm{N}$ and $\mathrm{P}$.

The government should strengthen the protection of the water environment of farmland area and set up purifying pond sewage ecological treatment system, which is of low cost and small occupation area. Purify farmland water pollutants through cultivated wetland and aquatic plants.

\subsubsection{Subsidy policy}

As we mentioned before, at present, agricultural non-point source pollution control seriously lacks subsidy policy. There are a lot of difficulties in the process of forming subsidy policy. The difficulties come from unreasonable development strategy, planning and policy management in the process of rural area shifting into an urban area. Because of the occurrence and influence of non-point source pollution are of universality, complexity and particularity, the control measures cannot simply copy the traditional methods and means for point source pollution (Lipin C and Xiaoyan). So here, the thesis suggests that the government should explore policy measures that are corresponding with the characteristics of non-point source pollution (Pin H and Jiaji 1999). Some developed countries have made positive and effective exploration and practice in this respect (Malik et al. 1994). Since 1990, the EPA of the United States gave high subsidy to the states that developing agricultural non-point source control plan and providing technical and financial support to farmers in the adoption of Best Management Practices measures. Since the mid 1980s, the German government paid subsidies to the farmers of the water environment protection zone. The subsidies for promoting the development of ecological agriculture are up to about 4.8 billion, accounting for $18 \%$ of the total amount of agricultural investments. The European Union revised Common Agricultural Policy to give subsidies to farmers that reducing livestock density, fertilizer and pesticides in 1992. The EU secondly adjusted the agricultural policy fundamentally and increased the subsidies for the farmers that 
adopting environmentally friendly mode of production. The results show that, the use of economic instruments is more flexible and effective in the non-point source pollution control and management than ever. (Shortle et al 1998).

For a long time, China has implemented various subsidies to agriculture and greatly promoted the development of agriculture. But China's agricultural subsidies are not related to environmental protection tightly and some are even counterproductive (Xiaowen 2006). Therefore, strengthening the control and management policy of nonpoint source pollution in China (especially agricultural non-point source) and implementing the control management basing on the economic incentive model is the key to solve the agricultural non-point source pollution.

In the aspect of agricultural non-point source pollution control and management, subsidies are divided into three types: subsidies for a positive externality; subsidies for reducing the negative externality and price subsidies.

\section{(1) Subsidies for positive externality}

The government should establish policies for returning farmland to forest; construction of cultivated wetlands; promotion of eco-agricultural engineering and technology; and the establishment of waste treatment of rural wastewater field and feces of livestock. On the one hand, the operator can get real benefits from the related products. At the same time, the behaviors of the operators also have environmental benefits, namely the external benefits of society. However, the external benefits of society are not considered by operators in their production decisions. In this way, the optimal production scale and output of operators are not the best for society. In this situation, the government should focus on the principle of maximum social benefits and give appropriate subsidies to operators for expanding production scale and increasing output. The amount of subsidies is exactly equal to the external benefits.

1) Basic model

When there are no positive externalities, the operators of pursuit of maximum profits will make their production scale or output in $\mathrm{Q}_{0}$ according to the principle of $\mathrm{PMR}=\mathrm{PMC}$. At this point, the social benefit is also the most, as showed in Figure 3. When the unit product can bring positive external benefit (XR), according to the principle of optimization, the socially optimal production should be in $\mathrm{Q}_{\mathrm{E}}$ according to the principle of SMR=SMC. However, in this situation, only if the government gives operators subsidies of XR per unit product, the benefit curve of the operator will move upwardly to be coincident with social benefit curve. Then, the operator is willing to make the production scale expansion from $\mathrm{Q}_{0}$ to $\mathrm{Q}_{\mathrm{E}}$. 


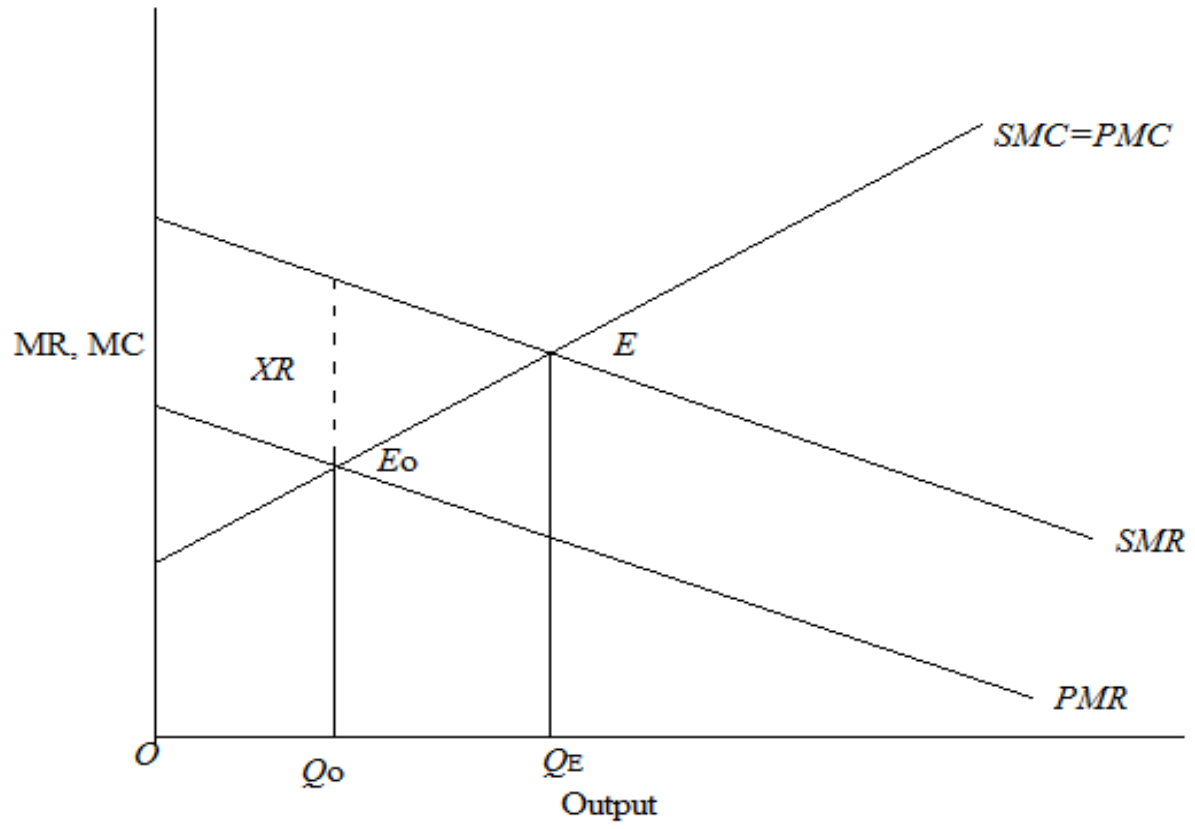

Figure 3 the positive external geometric model of subsidy

\section{2) Effect analysis of subsidy}

As shown in Figure 4, since the producers get subsidies XR from the government, the production of positive externalities increase from $\mathrm{Q}_{0}$ to $\mathrm{Q}_{\mathrm{E}}$, the market supply curve is shifted from $\mathrm{S}_{0}$ to $\mathrm{S}_{1}\left(\mathrm{XR}=\mathrm{AE}=\mathrm{E}_{0} \mathrm{~B}=\mathrm{P}_{2}-\mathrm{P}_{1}\right)$ and the price of the product decreases from $\mathrm{P}_{0}$ to $\mathrm{P}_{1}$. Subsidies effects on different subjects are analyzed as follows: 


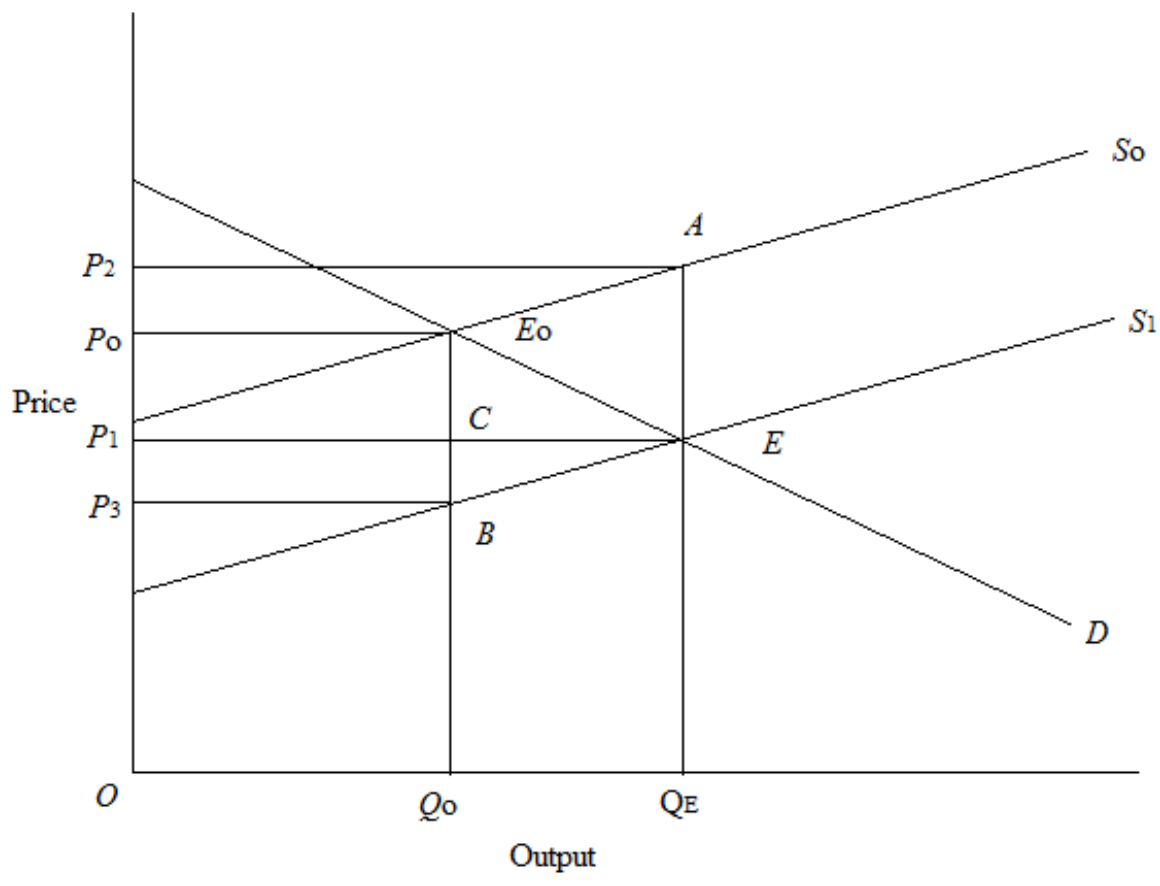

Figure 4 Analysis of the effects of subsidies for positive externalities

a. The effects on producer. The producer surplus is the area of triangle $\mathrm{P}_{0} \mathrm{E}_{0} \mathrm{P}_{1}$ before subsidy. The producer surplus is the area that is below the price the line $\mathrm{P}_{1}$ and above supply curve $\mathrm{S}_{1}$ after subsidy. Obviously, producer surplus increases and the incremental area is the area of $\mathrm{P}_{1} \mathrm{EBP}_{3}$, which is also equal to the area of $\mathrm{P}_{2} \mathrm{AE}_{0} \mathrm{P}_{0}$.

b. The effects on consumer. Subsidies can let consumers buy agricultural ecological products at a low price. The consumer's surplus increases at the same time. The incremental area is the area of $\mathrm{P}_{0} \mathrm{E}_{0} \mathrm{EP}_{1}$.

c. The effects on government. The government needs to pay subsidies in order to encourage the construction of agricultural ecological environment. The amount is the area of rectangular $\mathrm{P}_{2} \mathrm{AEP}_{1}$.

d. The effects on the environment. The subsidies not only increase agricultural ecological construction and environmental protection, also improve the agriculture ecological environment quality. From the point $\mathrm{Q}_{0}$, each additional unit of output will get external environmental benefit XR. Increasing output $\left(\mathrm{Q}_{\mathrm{E}}-\mathrm{Q}_{0}\right)$ can get environmental benefits of $\mathrm{XR} \cdot\left(\mathrm{Q}_{\mathrm{E}}-\mathrm{Q}_{0}\right)$, which is exactly equal to the area of diamond $\mathrm{AE}_{0} \mathrm{BE}$.

e. The net social benefit of the subsidy. The net social benefit after the implementation of subsidies is the sum of all the effects above, which is the sum of the increase in 
consumer surplus, the producer surplus and the environmental benefits. Then subtract the government subsidies. This is:

$$
\mathrm{S}_{\mathrm{P} 1 \mathrm{EBP} 3}+\mathrm{S} \text { P0E0EP1+S AE0BE-S P2AEP1 }=\mathrm{S}_{\mathrm{E} 0 \mathrm{~EB}}
$$

Therefore, the government gives a subsidy to the producers of the positive externality of production is economical and reasonable from the social point of view.

3) Calculation of positive external subsidy

To determine the positive external subsidies, the essence is the calculation of external environmental benefit except for production activities. For the control of agricultural non-point source pollution, it is the evaluation of environmental benefits produced by returning farmland to forest and grassland, construction of cultivated wetlands, establishment and promotion of eco-agricultural engineering and technology, waste treatment of rural wastewater and feces of livestock.

The evaluation methods are market value method, shadow engineering method and the human capital method. Using the market value method can estimate the environmental benefits produced by returning farmland to forest and grassland, construction of cultivated wetlands, establishment and promotion of eco-agricultural engineering and technology. If these measures can reduce soil erosion, protect water and improve water quality, then they can increase crop yield and quality, reduce the cost of purifying water quality and increase the economic benefits of water supply area. Using the shadow engineering method can calculate the ecological benefit of pollutant removal and water conservation produced by returning farmland to forest and construction of cultivated wetlands. Using the human capital method can calculate the benefits produced by the establishment and promotion of eco-agricultural engineering and technology, waste treatment of rural wastewater and feces of livestock.

(2) Subsidies for reducing the negative externality

The farmers engaged in agricultural production, will inevitably have a negative effect on the environment. In order to achieve environmental planning goals, the key is to guide farmers to change the existing mode of production and life and reduce the amount of pollution gradually. In the key water source protection areas, the government should require farmers not engage in the production of the negative externality and even production can produce the positive external effect. But in most watersheds, ecological construction and environmental protection activities of strong positive externalities are often regarded as public goods and provided directly by government. In terms of the agricultural population of Qiandao Lake, what matters is how to stimulate farmers to reduce production intensity or change the mode of production and life through subsidies means, thereby reducing the negative external effect. 
This subsidy can be given to those: farmers who returning farmland to forest in accordance with the environmental planning requirements, farmers who reducing fertilizer and pesticide application, farmers who applying harmless organic fertilizer and farmers who establishing waste treatment of rural wastewater and feces of livestock.

In theory, same with the principle of the positive external subsidies, the subsidies of a negative externality should use reduced amount of money for negative externalities as standard, but this requires an assessment of environmental and economic effects of complex reduced negative externalities. In order to make, the formulation and implementation of policy is more convenient and feasible. The government can adopt the following methods: the subsidies of the returning farmland can use the average monetary loss of no longer farming as standard, the subsidies of chemical fertilizer and pesticide users can use the average monetary loss of the reduced crop yields as a basis.

\section{(3) Subsidies for price}

The economic policy that controls the amount of products includes the product user fees and subsidies of the product price. The purpose of the former is to limit and reduce the use of products that are harmful to the environment, such as agricultural chemicals tax. Subsidies of the product price encourage farmers to use green agricultural products of non-toxic, low toxicity and high efficiency. Such as commercial organic fertilizer that contained a variety of mineral nutrient elements and organic matters. Organic fertilizer is also the ideal fertilizer for nourishing the soil and increasing the yield and quality of green agricultural products through harmless treatment. For a long time, the farmer has relied on fertilizer because of the convenience and applied blindly, which causes the declining quality of agricultural products and environmental pollution.

To change the selections of fertilizers by farmers, the feasible policies are using the market price deference of effective components of organic fertilizer and chemical fertilizer as a standard for subsidy; making the organic fertilizer price is equal to or even less than the price of chemical fertilizer to enhance market competitiveness of organic fertilizer; Encouraging producers and farmers to produce and use harmless organic fertilizer. The objects of subsidies can be commercial organic fertilizer producers for reducing the cost of the unit yield of organic fertilizer production or organic fertilizer buyers.

(4) Other economic benefits (indirect) policy

Similar to the method of direct subsidies, other economic policies for encouraging farmers to take measures to reduce environmental pollution are: government investment, loans of low interest or no interest, namely the government provides low 
interest loans or free interest loans to pollution operators that take all kinds of engineering and technical measures, tax reduction and exemption, namely the government supports the operators that adopt pollution prevention measures through accelerated depreciation, exemption and rebate.

The general rate of return on investment in environmental protection industry is relatively low and even unprofitable in a period time. Investment cannot get returns if completely rely on market self-regulation in the short term, so the government should implement a policy of investment credit and the investment tax rebate to encourage producers to invest. These policies are also known as an indirect subsidy.

The subsidies can be given to following construction projects: technical measures of controlling the soil erosion and pollution, such as water conservation, interception of flood and sediments, cultivated wetland and oxidation pond, biological purification, agricultural eco-engineering, waste disposal, innocuous treatment of livestock and poultry manure (or green organic fertilizer industry), ecological agriculture and organic agriculture technology promotion.

(5) The source for subsidy funds

The subsidy is government expenditure on the surface. But, in fact, it is a transfer payment. The funds mainly come from two aspects: 1 ) the water pollution taxes based on the principle of polluter pay. In the river basin pollution control policy, taxes and subsidies are pairs of twins. They are a complement of each other. 2) Beneficiaries of environmental improvement pay environmental resources user fee. According to the principle of compensation for use, the water environment protection behavior should be subsidized by consumers of downstream water resource. Compensation can be charged by raising the price of water.

\subsubsection{The advantages of the policy model}

According to the previous analysis, all the measures above are exactly suited for the ANPSP problems in China. Compared with the current ANPSP control policies of China, the policy model of this paper has many more advantages and becomes a better way to deal with the pollution problems. The main advantages are as follows:

(1) Change from controlling the ANSPS in the end to control pollution in the entire process.

Environmental management policy of China mainly concentrates in the field of production and focuses on the end treatment of industrial pollution, which is ignoring the distribution, circulation and consumption areas. The policy model of this thesis puts forward some measures that are not only controlling the pollution from the source. Also, a lot of measures are taken before or during the pollution has occurred. For 
example, the governance policy is made to prevent the agricultural non-point source pollution, and the legislation is made to control the pollution that has already existed. The technical system and the economical subsidy policies control the pollution in the whole process. Compared with the current Chinese ANPSP control policy, the policy model begins to realize the transfer of control policy from micro to macro and from the tail to the source. It is a fundamental reform of the system of ANPSPS control and breaking the previous "deal with the pollution from one aspect" think model in the field of environmental policy. Also, the policy model realizes the combination of "point-line-surface" and form a full integration of environmental policy mechanism.

(2) Change from single instruction control means to the comprehensive administrative, economic and technological means

Because of the long-term implementation of planned economic system, in the field of environmental protection, China mainly uses single administrative means to control pollution. With the changes in the Chinese market economic system, the policy model of the thesis is suitable for Chinese social and economic environment. The policy model transfers from a single command control policy to a variety of environmental policy means of administrative, economic and technological, especially the more widely use of economical means, which will have a positive influence on the work of environmental protection in China.

At the same time, in view of the tendency of enterprise resist the environmental policy, a voluntary environmental policy is also included in the policy model. This policy is based on a voluntary basis of enterprise to promote the increase of environmental protection investment, while effectively reducing the government's responsibility. During the development process of a series of environmental policy, government regulation function decreases, the role of government changes from the environmental policy agents into environmental policy guidance, enterprises change from passive recipients to active participants in environmental policy.

(3) Add the ecological subsidy policy to the control system

Ecological compensation is an economic policy that China is very concerned about in recent years. However, there are no integrated subsidy policies in the ANPSP control system in China. The ecological compensation mechanism designed by this thesis has paid particular attention to the definition of the central and local duties and focused on the ecological compensation policy framework that is based on the situation of China. Also, the policy model proposed policies of ecological compensation mechanism based on water source protection.

All the advantages of the policy model provided by this thesis show that the policy model firstly integrate the ANPSP control measures in four important aspects, and 
introduce ecological subsidy policy creatively, which makes the policy model a best approach to deal with the ANSPS problem in China.

\subsection{Conclusion and enlightenment}

This chapter firstly provides a map of policy tools for the readers in the aspect of the available policy instruments. Most of these tools have been applied in the control of agricultural non-point source pollution, no matter in theory or practice. The purpose of the map is to provide proper references for the policy designers.

In the policy design part, the paper introduces a control policy model based on governance policy, environmental legislation, technical system and subsidy policy. The categories of the model do not have strict theoretical basis and is not complete at some level. However, it at least provides the main control policies for the readers.

This chapter then reviews some scholars' evaluation on various policy tools and the results, which can help policymakers to identify which tool is the best suitable for a special class of water quality problems.

This chapter reviews and summarizes the research on non-point source pollution control policy, and provides an important theoretical basis for the follow-up case research. The research gives us at least the following enlightenments:

(1) The main task of economists is to design the incentive policy and let the farmers consider the costs of pollution in its decision frame, which is also the basic goal of the non-point source pollution control policy.

(2) Through policy design to realize the economic efficiency (optimal) is usually not possible, for a resource management departments, the ideal result is to realize the special environmental goals with the minimum cost (cost effective output), such as reducing fertilizer use in the area.

(3) The most difficult part for agricultural non-point source pollution control is that the information is not sufficient, namely the supervision cost of whether the non-point source is polluted or whether the policy is implemented is very high. Different policy instruments are different in the information cost, the supervision cost and the execution cost. Specifically, some policy tools do not have high requirements on the information cost, but the implementation and supervision cost is very high (e.g. command-control tool). On the contrary, some policy tools are of high demands on the design of information cost, but the supervision cost is relatively low (e.g. tradable permits). Other policy tools have a high information cost, at the same time the execution cost is also very high (e.g. performance taxes). Therefore, in the selection of the policy tools, the government must take account of these characteristics. Otherwise, it is difficult to achieve the goals of cost-effectiveness. However, the actual 
operation is very difficult, and it has become one of the main reasons for the policy design of the control of non-point source pollution is challenging.

(4) The government unable to evaluate the superiority and inferiority of the policy tools. On the one hand, each tool has its advantages and disadvantages. On the other hand, which tool is best depends largely on the site features of the nonpoint source pollution. 


\section{Chapter 4 Analysis of natural ecological structure of Qiandao Lake}

From Chapter 4, the thesis will start with the case analysis of Qiandao Lake. In the following chapter, the thesis is going to study the natural and social status of Lake Qiandao, while analyzing the ANPSP situation and related influence factors of ANSPS in Lake Qiandao. Coordinated with the "Xin'anjiang reservoir water source protection project" of Zhejiang Provincial Water Conservancy Bureau in 2010, the thesis plans to establish practical economic policy for Lake Qiandao and achieve the following goals: changing production mode and behavior that is not conducive to the protection of water resources within the basin before 2015, which is including the following area: 1) no land farming and other business activities below the water line of $155 \mathrm{~m}$ in the water source protection areas. 2) Preventing the use of chemical pesticide and no rice planting in the water source protection area. 3) In the upstream of the reservoir, establishing three soil-water conservation defenses to cultivate grass and naturally repair, maintaining and improving the water quality of the reservoir, which ensures to provide high quality drinking water. At the same time, it hopes the study results can help to encourage the development of ecological agriculture in the local area and improve people's income and standard of living. It hopes that the case study will make an example for other basins of China to choose the proper control policy from the policy model for their ANSPS problems based on the natural and social situation.

\subsection{The natural environment situation}

\subsubsection{The geographical location and the hydrological characteristics}

Qiandao Lake is located in the west of Zhejiang (29 36'33"N 118 59'24"E), China and about 150 kilometers from the city of Hangzhou. It is an artificial lake formed after the completion of the Xin'an River hydroelectric station. In 1959, in order to build the Xin'anjiang Reservoir the valley was flooded with water resulting in a lake. The area of the lake is $573 \mathrm{~km}^{2}$ with a storage capacity of $17.8 \mathrm{~km}^{3}$. The length is $150 \mathrm{~km}$ from south to north, and the width is $10 \mathrm{~km}$. The lake is so called because it is dotted with 1,078 large islands and a few small ones.

\subsubsection{Geology and geomorphology}

The soil of the basin belongs to the old land in the south of the Yangtze River and the development of the formation is good (Compilation Committee of Chun'an County, 1990). There are different rock types, such as sedimentary rocks, igneous rocks, and metamorphic rocks. Lithology is very different, and the structure is complex.

The situation of terrain is that the four edges are high, and the middle is low. It is tilted from west to east. Geomorphic type is very rich, mainly are low mountains and hills. 
The low hills and mountains below an elevation of $108 \mathrm{~m}$ are submerged by the water to form the Qiandao Lake after Xin'anjiang reservoir starting to impound water.

\subsubsection{Meteorology and water temperature}

The Qiandao Lake is located in the subtropical monsoon average temperature zone, and the climate is warm and humid. There are abundant rainfall, sufficient light and four distinct seasons (Chun'an County Department of Statistics, 2000). The annual average temperature of the lake area is $17^{\circ} \mathrm{C}$. The annual average frost-free period is 263 days, and the average annual frozen period is 23.4 days. The annual average rainfall is $1675.7 \mathrm{~mm}$, and the annual average rainfall day is 155 days. Annual average relative humidity is $76 \%$, and the annual average sunshine hours are 1951 hours. The annual average evaporation is $1381 \mathrm{~mm}$. The annual average wind speed is $2.1 \mathrm{~m} / \mathrm{s}$. Wind direction varies with the seasons change. Vertical climate changes significantly, and flood disasters are frequent.

Water temperature can be divided into three levels: the temperature varies between 10$30{ }^{\circ} \mathrm{C}$ from the surface of the lake to $10 \mathrm{~m}$ under the lake, and this area is called an epilimnion. The area from $10 \mathrm{~m}$ to $35 \mathrm{~m}$ under the lake is called thermocline, which varies with the weather temperature. From the depth of $35 \mathrm{~m}$ below the thermocline layer is called the hypolimnion and perennial water temperature maintained at $10{ }^{\circ} \mathrm{C}$.

\subsubsection{Soil}

The types of soil in Qiandao Lake can be divided into red soil, yellow soil and rock soil (Chun'an County Soil Survey Office, 1987). The thickness of the soil layer is 30$60 \mathrm{~cm}$, and organic matter content of the soil is only $3.11 \%$. The nitrogen content is $0.152 \%$, and phosphorus content is $6.6 \mathrm{ppm}$. The soil is acidic.

The area of red soil is 4121000 acres, which are about $62.1 \%$ of the total area of Chun'an County. The red soil is mainly distributed on the low mountains and hills that are below an altitude of $700 \mathrm{~m}$. The $\mathrm{pH}$ of the soil is from 5.5 to 6.0 . The permeability of the soil is poor, so it is vulnerable to erosion. The area of yellow soil is 553000 acres, which are about $8.3 \%$ of the total area. The yellow soil is mainly distributed in hilly areas that are above an altitude of $700 \mathrm{~m}$. The $\mathrm{pH}$ of the soil is 5.5 . The area of rocky soil is 914000 acres, which is about $13.8 \%$ of the total area. The rock soil is mainly distributed in hilly areas that are below an altitude of $700 \mathrm{~m}$. The $\mathrm{pH}$ of the soil is above 7.0. Soil layer is thick. The land is fertile and permeable. According to the distribution, the soil can be divided into paddy soil, upland soil and mountain soil.

\subsection{Current situations of social and economic development} $60 \%$ of the Qiandao Lake basin is in Anhui Province, and the population is 1486000. Because of the rarity of documents, the social and economic condition of Anhui is hard 
to investigate. However, economic development has mainly relied on agriculture in Chun'an County of Zhejiang Province.

\subsubsection{The administrative division and population}

Chun'an County was merged by the original Chun'an and Sui' an County in 1958

before the construction of the reservoir. Its area is $4427 \mathrm{~km}^{2}$, and it is the largest county of Zhejiang province. The county has 12 towns and 25 villages. Qiandao Lake town is the seat of county government, is the political, economic, cultural, transportation and tourism service center. The county's total population is 449600 , including agricultural population of 397400, non-agricultural population of 52200. The population of Qiandao Lake town is 37300.

\subsubsection{Industrial and agricultural economy}

The industry of Chun'an County is underdeveloped. The county has only about 150 industrial enterprises, mostly based on processing properties, including metal smelting and processing, food processing, wood and bamboo products processing industry, and non-metallic mineral products industry.

Agriculture is mainly based on forest, and the main agricultural products are tea, mulberry, fruit and timber in addition to grain. Qiandao Lake is rich in fisheries resources; there are 80 kinds of fish.

After several years of efforts, the adjustment of industrial structure has an effect. Agriculture accounted for $28.4 \%$; industry and the construction industry accounted for $38.3 \%$, and the tertiary industry accounted for $28.4 \%$.

\subsubsection{Tourism economy}

The State Council listed Qiandao Lake as the first batch of national key scenic area in 1982. After nearly 20 years of developments and growth, tourist attractions continue to reform and improve. Qiandao Lake was named at the top of "Zhejiang top ten beauty" in 1997, and it is listed by the media as one of Chinese mainland tourism three hot spots. The tourism industry has become a leading industry in Chun'an County.

\subsection{Present situations of ecological environment}

\subsubsection{The structure of land use}

The total area of Chun' an County is 6641000 acres, of which the land area is 5918000 acres and the lake area is 723000 acres. The land area is mainly forest land area, which is 5244000 acres, accounting for $79 \%$ of the total area. Non-forest land area is 1397000 acres, accounting for $21 \%$ of the total area (Chun'an County Forestry Department, 2000). 


\subsubsection{Forest vegetation}

Vegetation of Qiandao Lake watershed is developed well and the forest coverage rate of $65.8 \%$. It is in the subtropical evergreen broad-leaved forest region. There are five natural vegetation types and seven cultivated vegetation types. Vegetation is roughly vertical distribution. There are citrus, peach, plum, tea and other artificial vegetation when is it below the altitude of $200 \mathrm{~m}$. Natural and artificial vegetation coexistent when it is in the altitude of $200 \mathrm{~m}-800 \mathrm{~m}$ and there are pine, fir, cedar, bamboo, etc. There is more natural vegetation and less artificial vegetation when it is in the altitude of $800 \mathrm{~m}-$ $1000 \mathrm{~m}$, such as Masson Pine, etc. The natural secondary vegetation is the main type when it is above the altitude of $1000 \mathrm{~m}$.

\subsubsection{Animal and plant resources}

The wild animal resources of Qiandao Lake basin are rich. There are 61 kinds of mammals, 90 kinds of birds, 50 kinds of reptiles, 16 orders 32 families 1800 species of insects, and 2 orders 4 families 12 species of amphibian. There are 15 families and 87 species of fishes in Lake Qiandao.

The terrain of Qiandao Lake is complicated, and the weather condition is superior, so it is rich in wild plant resources. There are 194 families 830 genera 1824 species of plants. There are 1000 kinds of Chinese herbal medicine resources and 40 kinds of wild fruit trees.

\subsection{The situation of non-point source pollution of Lake Qiandao and reasons}

\subsubsection{Soil erosion}

Farming leads to soil erosion. Chun'an knew as Mountain County; the farmers had to make use of sloping land for reclamation planting because of little arable land. Since the terrain is steep, intensive rainfall is easy to lead to soil erosion.

Due to the destruction of local forest vegetation, soil erosion problem in Qiandao Lake basin is very prominent. The main soil erosion is the water erosion, but there is also the existence of the gravitational erosion such as landslide, collapse, debris flow.

The area of water and soil loss of Chun'an is $775.1 \mathrm{~km}^{2}$, which is accounting for $17.5 \%$ of the total land area (Soil and Water Conservation Office of Chun'an County, 2000).

From the perspective of the land-use types, soil erosion is mainly concentrated in the woodland and the loss area is $649.7 \mathrm{~km}^{2}$. Erosion intensity ratio is higher in sloping land, and the loss area is $81.6 \mathrm{~km}^{2}$. 


\subsubsection{Chemical fertilizer pollution}

In order to improve the grain yield per unit area and meet the needs of food, the fertilizer input of Chun'an County has increased. According to the survey, fertilizer use of Chun'an County in year 2000 is about 84,000 tons and the unit application of fertilizer is $647.82 \mathrm{~kg} / \mathrm{ha}$. However, the total amounts of fertilizers of Zhejiang Province are 908,000 tons and the application level is $335.8 \mathrm{~kg} / \mathrm{ha}$ in the same year, which means the amount of fertilizers of Chun'an is higher than the provincial average (Chun'an County Department of Statistics, 2000). In the structure of fertilization, there is a large amount of nitrogen fertilizer but little potassium fertilizer. The proportion of elemental fertilizer is large, but the high concentration compound fertilizer and crop specific fertilizer are less. Organic fertilizers decrease significantly, and the green manure areas decrease sharply lead to an imbalance of the structure of fertilizer and reduced soil fertility and destruction of soil structure.

At the same time, because of the use of fertilizers, a lot of toxic and hazardous substances flow into streams, rivers from the fields, orchards, etc. Eventually, they flow into the Lake. According to the survey, the use of chemical fertilizers of Chun'an County in the year 2000 is 2.32 times of 1995's (Chun'an County Environmental Protection Committee, 2000).

\subsubsection{Pesticide pollution}

According to the analysis of statistical data of year1998-2000 (Chun'an County Department of Statistics, 2000), the national average level of pesticide use is $12.73 \mathrm{~kg} / \mathrm{ha}$ (active ingredient). At present, the most amount of pesticide use is in vegetables, fruit trees and grain crops (rice, wheat). Pesticides types use at present in Chun'an are insecticides, which are including a very high proportion of highly toxic. According to statistics (Chun'an County Department of Statistics, 2000), in 2000 organic phosphorus insecticides of Chun' an County are still accounting for $39.4 \%$ of the total amount of pesticides and $70.5 \%$ of the total amount of insecticides.

Unreasonable use of pesticides in a long time will inevitably lead to soil, surface water, groundwater and agricultural pollution. Pesticide application amount exceeds the standard is the fundamental reason of the pollution, which is related to the farmer's lack of pest management knowledge and the lack of technology promotion service of the government to a great extent. According to pesticide behavior research of farmers a few years ago, more than $1 / 3$ of farmers did not know the harm of pesticide on the human body and the environment. In addition, there are $65 \%$ of the farmers do not understand the natural enemy of the pest or pest controlling concept. In the aspect of technical information, only $34 \%$ of the farmers said they got technical guidance of the pesticide application from the technical department (Guoyan 2000). Due to technical guidance does not update, there are more than $84 \%$ farmers exceed the standard 
application of pesticide. According to statistics and research materials, pesticide contaminates soil mainly in the residues of organic chlorine pesticides (Chun'an County Environmental Protection Committee, 2000).

\subsubsection{Lake eutrophication status}

In the past 10 years, due to rapid economic development, increased population and the intense use of lakes, the pollution of the lake water, especially eutrophication has become a serious environmental problem. However, the water pollution control and protection measures are not established in time. The increasing eutrophication of lakes and the degree of eutrophication are closely related to phosphorus (Zongshe 1998). Along with the strengthening of point source control, non-point source pollution has become main influence factors of Lake Eutrophication in Chun'an County. According to statistics (Chun'an County Environmental Protection Committee, 2000), non-point source pollution (including human and animal excrement and sewage) has become the main source of total nitrogen and phosphorus load of Qiandao Lake.

\subsubsection{Agricultural straw pollution}

With the changes in the structure of regional energy, more people use crop stalks as life. Straw utilization of Chun'an is significantly higher than the average level of utilization of Hangzhou. A lot of straw are burned in the field ditch or lake, then organic matter of stalks gets into the water by rain and decay, thus causing serious pollution. 


\section{Chapter 5 Quantitative analysis of the relationship between the ASPSP and the soil types of Lake Qiandao}

\subsection{Quantitative analysis of runoff}

\subsubsection{Foreword}

Rain drop on the surface of farmland soil, some of them infiltrate into the soil, some are evaporated, and others form runoffs. The main problem is that the dissolved nitrogen, phosphorus, and sediment from runoff not only lead to loss of soil fertility, but also pollute rivers. Therefore, studying the relationship between the runoff amount and soil types contributes to the formulation of management policy of agricultural nonpoint source pollution control and provides the technical basis for the formulation of the control policy. This thesis will rely on the study of Huanchun (2010) and quantitatively analyze the relationship between the agricultural non-point source pollution and different soil types.

\subsubsection{Method}

Set the runoff plots in four different types of lands (vegetable garden, dry land, bamboo garden, chestnut forest) and collect the runoff amounts after rain. All the experimental data of this paper come from the report of Huanchun Lv (2010) ${ }^{\mathrm{i}}$.

According to the Zhejiang province rainfall statistics yearbook, the rainfall of Chun'an County from May 24, 2011 to September 6, 2011 is shown in table 5.1-1 (The statistic yearbook of Zhejiang Province, 2011). For the convenience of analysis, regard the continuous rainfall time as a single rainfall event, and there are eight rainfall events.

Table 2 Rainfall event classification table

\begin{tabular}{|c|c|}
\hline Rainfall event (date) & Rainfall $(\mathrm{mm})$ \\
\hline 5.24 & 16.0 \\
\hline 6.22 & 10.7 \\
\hline 7.1 & 12.5 \\
\hline 7.5 & 110.8 \\
\hline $7.19-7.20$ & 48.0 \\
\hline 7.22 & 33.6 \\
\hline 8.26 & 11.5 \\
\hline $9.5-9.6$ & 23.5 \\
\hline
\end{tabular}




\subsubsection{The characteristics of different lands' runoffs}

When the land use types are dry land, vegetable garden, and woodland, rainfall is not immediately generate runoff. Since the runoff is consumed by vegetation, soil infiltration and evaporation, only when the intensity of rainfall is larger than the soil infiltration rate, or continuous low intensity rainfalls make soil moisture content approach saturation, the surface soil begins to generate runoff.

According to the experiment in runoff plots of four different lands use in the basin Jiekou, the monitoring data of two rainfall events come from the report of Huanchun Lvi'. Comparison of runoffs of various lands use types is as shown in Figure 6.

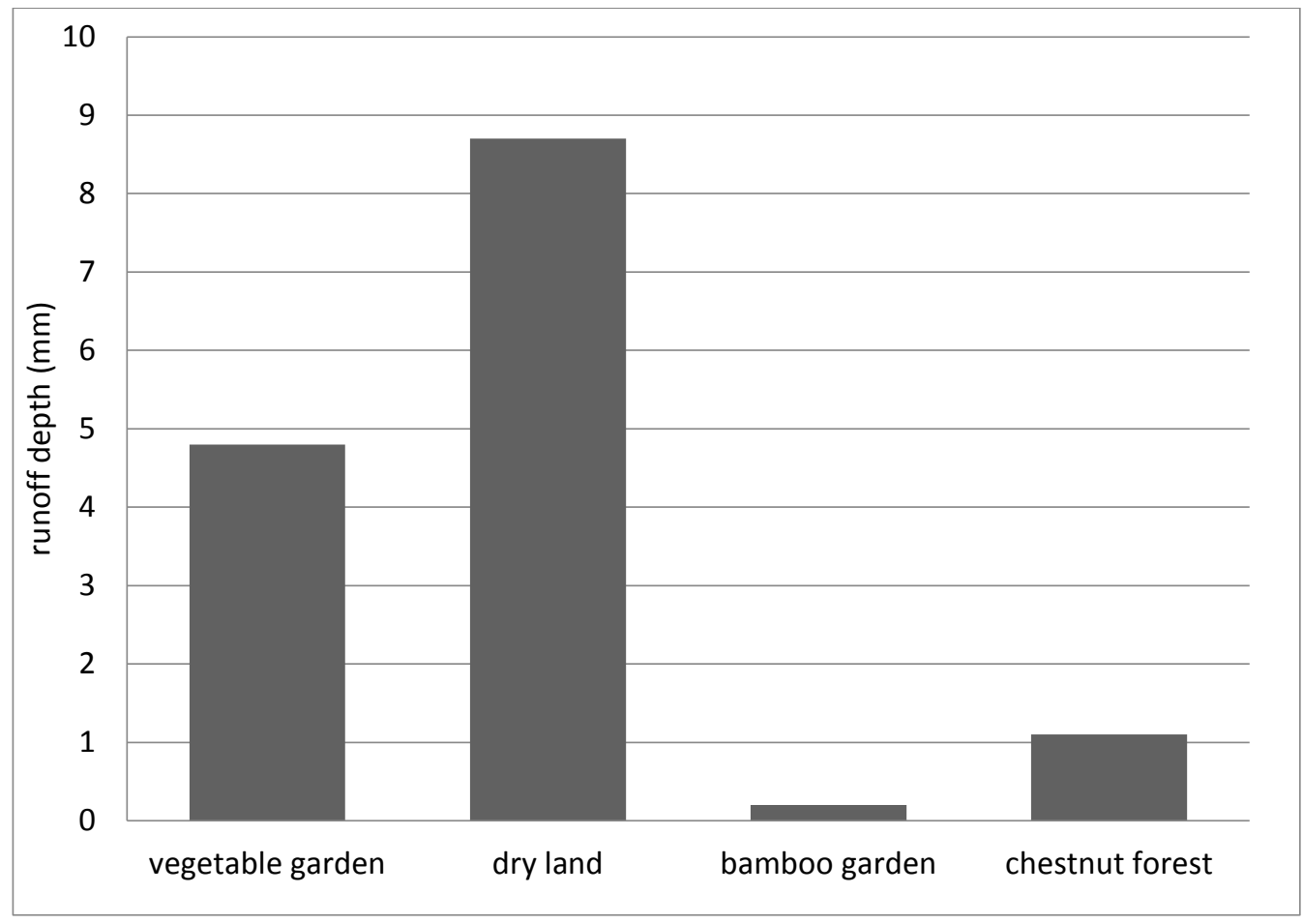

Figure 5 Plot surface runoff of the rainfall on July 19th, 2011 
We can see several characteristics from Figure 6:

(1) Crop coverage and soil conditions of different lands are different, so the rainfall runoff characteristics have obvious differences.

(2) Runoff volume of dry land is the most, because there is no coverage of vegetation or corps. Vegetable garden's coverage is slightly higher, so runoff volume is less than dry land. The runoff volume of chestnut forest is less than the runoff of the vegetable garden, because the surface of chestnut forest is covered with grains and grass. The surface of bamboo garden is not only covered with grains, but covered with a layer of rotten leaf. So its runoff volume is the least.

\subsection{Nitrogen and phosphorus loss quantitative analysis}

\subsubsection{Foreword}

The production and output of agricultural non-point source pollution depend on many factors. Rainfall-runoff-pollution is recognized as a pollutant generation mode.

Rainfall is the reason of the farmland soil erosion, the loss of nitrogen and phosphorus in surface runoff is the main way of soil nutrient loss and is the main reason of ANPSP.

\subsubsection{Method}

Use the data and method of Huanchun Lv's (2010). Experiments were carried out in conditions of natural rainfall. Use the method of synchronous monitoring to study nitrogen and phosphorus concentration of different types of lands (vegetable garden, dry land, bamboo garden, chestnut forest) in the study area Jiekou watershed

\subsubsection{Nitrogen loss analysis in different land uses types.}

For a description of nitrogen loss in different land use types, we will use the results and method of Huanchun Lv's (2010). Set runoff plots in four different types of lands (vegetable garden, dry land, bamboo garden, chestnut forest) and discusses the output of nitrogen concentration variation rules in different lands uses according one rainfall event. Specific variations of nitrogen concentration are in the Table 3 
Table 3 the Nitrogen concentration of runoff in different types of lands use in the rainfall event of July 19th, 2011

\begin{tabular}{|c|c|c|c|c|c|}
\hline Lands types & \multirow{2}{*}{$\begin{array}{c}\text { Sample } \\
\text { amount }\end{array}$} & \multicolumn{2}{|c|}{$\begin{array}{c}\text { Concentration of } \\
\text { TD(mg/L) }\end{array}$} & \multicolumn{2}{c|}{$\begin{array}{c}\text { Concentration of } \\
\text { DN(mg/L) }\end{array}$} \\
\cline { 3 - 6 } & & Average & Rage & Average & Rage \\
\hline $\begin{array}{c}\text { Vegetable } \\
\text { garden }\end{array}$ & 10 & 12.97 & $9.27 \sim 15.66$ & 11.96 & $8.63 \sim 13.99$ \\
\hline $\begin{array}{c}\text { Dry land } \\
\text { Bamboo } \\
\text { garden }\end{array}$ & 10 & 4.66 & $3.49 \sim 5.89$ & 3.79 & $2.48 \sim 4.97$ \\
\hline $\begin{array}{c}\text { Chestnut } \\
\text { for }\end{array}$ & 5 & 2.04 & $1.40 \sim 2.41$ & 1.75 & $1.35 \sim 2.30$ \\
\hline
\end{tabular}

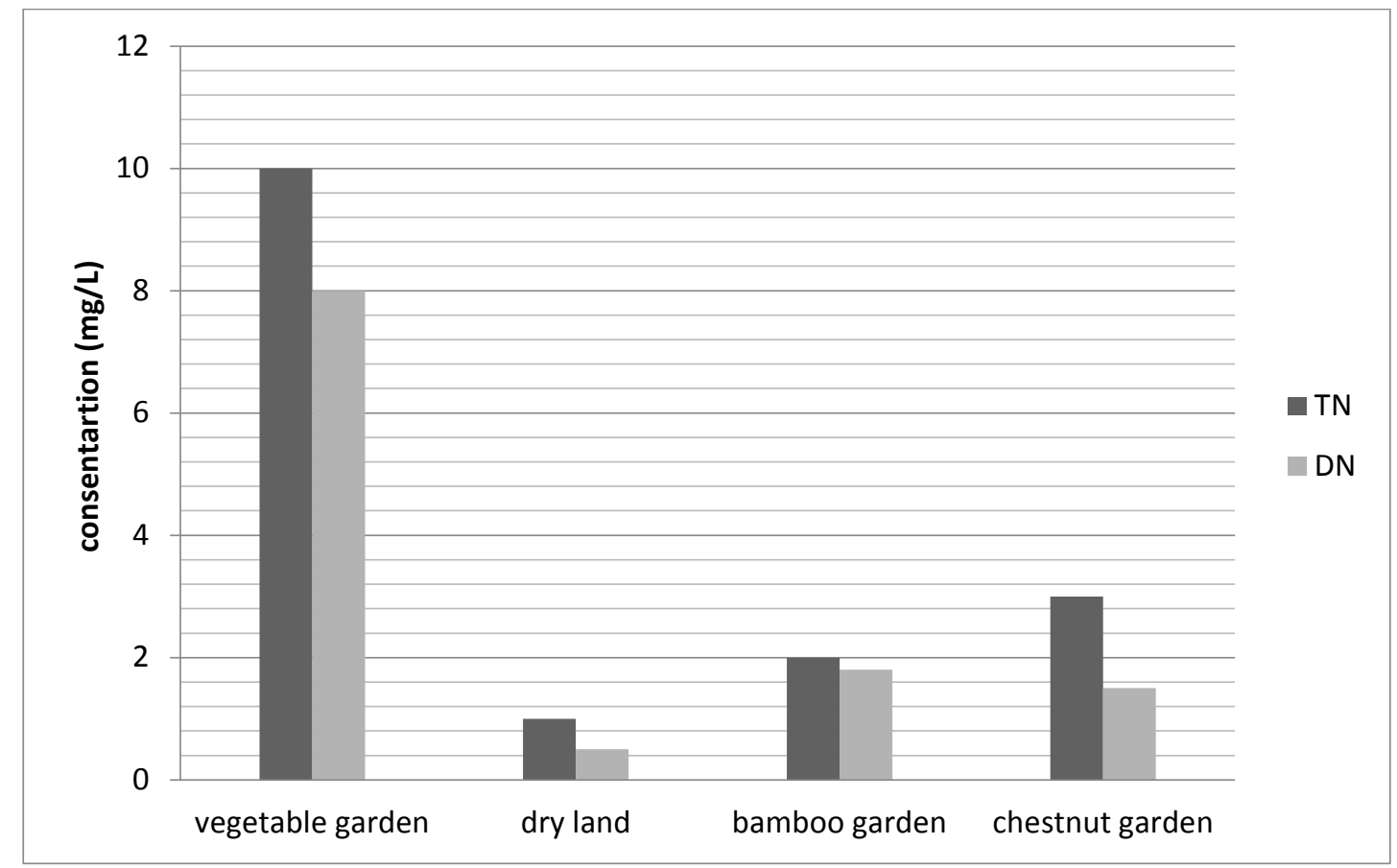

Figure 6 The nitrogen output concentration of runoff in different types of lands use in the rainfall event of July 19th, 2011 
As can be seen from the tables and figures, tendency of the change of dissolved nitrogen concentration is consistent with the variation of total nitrogen. The TN concentration and DN concentration are very similar in the bamboo garden. TN concentration is slightly larger than DN concentration in the vegetable garden. Overall, the average output of the TN concentration order is: vegetable garden $>$ chestnut forest $>$ bamboo $>$ dry land. The order of output concentration of DN is similar with the order of TD concentration.

\subsubsection{Phosphorus loss analysis in different land uses types}

For a description of phosphorus loss in different land use types, we will set runoff plots in four different types of and discusses the output of phosphorus concentration variation rules in different lands uses according to two rainfall events. Specific variations of phosphorus concentration are in the Table 4 and Figure 8

Table 4 the phosphorus concentration of runoff in different types of lands use in the rainfall event of July 19th, 2011

\begin{tabular}{|c|c|c|c|c|c|}
\hline Lands types & \multirow{2}{*}{$\begin{array}{c}\text { Sample } \\
\text { amount }\end{array}$} & \multicolumn{2}{|c|}{$\begin{array}{c}\text { Concentration of } \\
\mathrm{TP}(\mathrm{mg} / \mathrm{L})\end{array}$} & \multicolumn{2}{c|}{$\begin{array}{c}\text { Concentration of } \\
\mathrm{DP}(\mathrm{mg} / \mathrm{L})\end{array}$} \\
\cline { 2 - 6 } & & Average & Rage & Average & Rage \\
\hline $\begin{array}{c}\text { Vegetable } \\
\text { garden }\end{array}$ & 10 & 1.854 & $1.153 \sim 2.577$ & 1.279 & $0.764 \sim 1.732$ \\
\hline $\begin{array}{c}\text { Dry land } \\
\text { Damboo }\end{array}$ & 10 & 0.362 & $0.212 \sim 0.850$ & 0.036 & $0.012 \sim 0.083$ \\
\hline $\begin{array}{c}\text { garden } \\
\text { Bayyyy} \\
\text { for }\end{array}$ & 3 & 0.167 & $0.147 \sim 0.182$ & 0.101 & $0.096 \sim 0.105$ \\
\hline $\begin{array}{c}\text { Chestnut } \\
\text { for }\end{array}$ & 5 & 0.749 & $0.652 \sim 0.834$ & 0.552 & $0.509 \sim 0.586$ \\
\hline
\end{tabular}




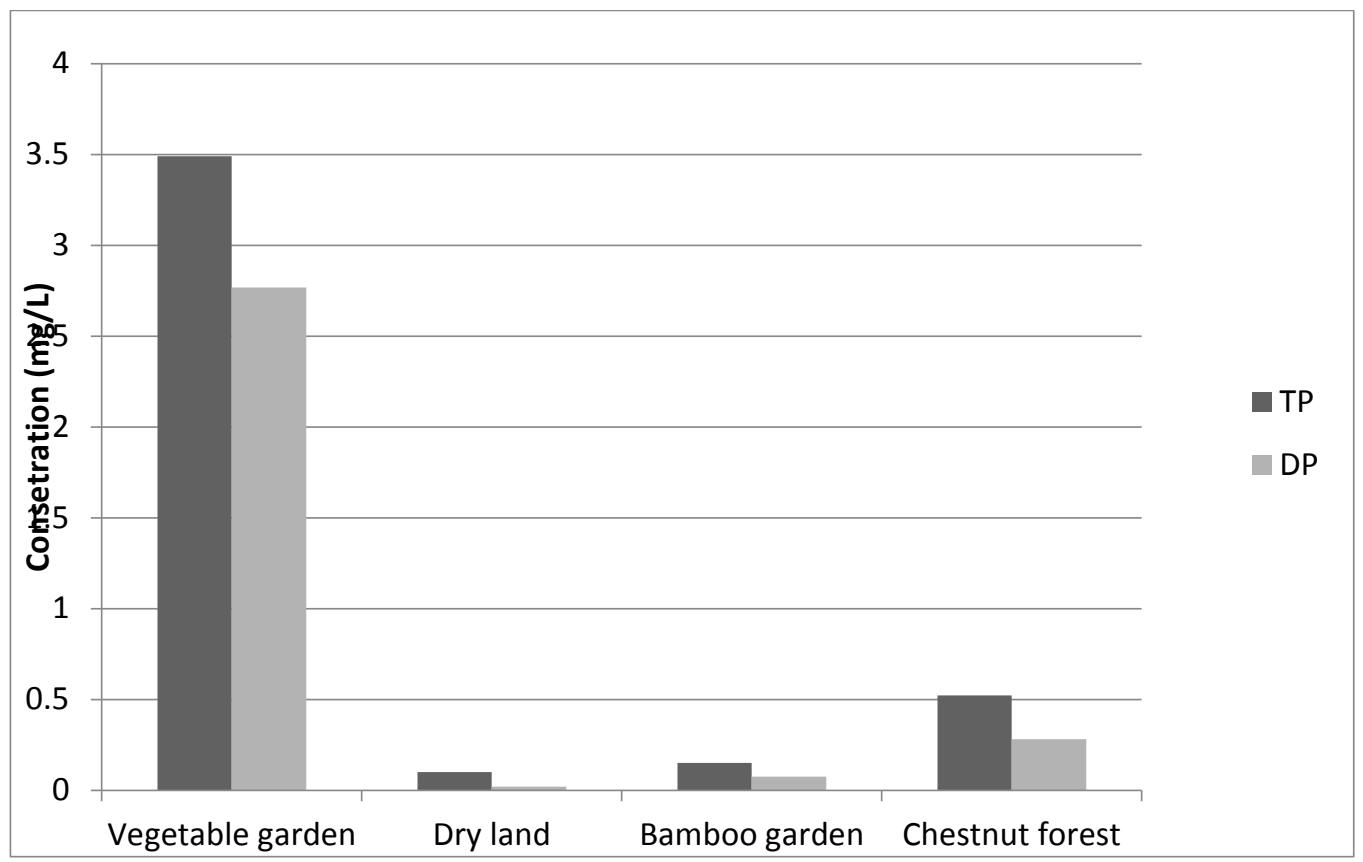

Figure 7 The phosphorus output concentration of runoff in different types of lands use in the rainfall event of July19, 2011

As can be seen from the tables and figures, tendency of the change of dissolved phosphorus concentration is consistent with the variation of total phosphorus in the different types of land plots. The total phosphorus concentration and dissolved phosphorus concentration is very different in the dry land. Dissolved phosphorus concentration is accounted for more than half of the total phosphorus concentration in the vegetable garden, dry land and chestnut forest due to rain making particulate phosphorus content increase. Overall, the average output of TP concentration order is: vegetable garden $>$ chestnut forest $>$ bamboo garden $>$ dry land. The output concentration order of DP is similar with the order of TP concentration

\subsection{Control measures}

From the quantitative analysis of the relationship between runoff and soil type, we can see that the runoff depth of the dry land is the most. The reason is that there is no vegetation on it, so it is easy to generate runoff, which is the main carrier of ASPSP. Therefore, this result shows that the proper amount of vegetation is needed for the control of the runoff, thus reducing the risk of generating pollution in the Lake. However, from Figure 6, the runoff depth of the vegetable garden is also very high, which makes us realize not only the vegetation amount is important. Also, the types of vegetable should be considered. The runoff depth of bamboo is the least. The reason is that the surface of bamboo garden is not only covered with grains, but covered with a layer of decayed leaf. Therefore, runoff data of different 
land use shows a fact that the farmers should return the farmland to trees or grassland for prevention and control of ASPSP.

From Figure 8 and 5.2-2 we can see the concentration of nitrogen and phosphorus is the most in the vegetable garden. The reason is that the farmers have to apply fertilizer and pesticide for the normal output. However, the production behavior of applying fertilizer and the high risk rate of runoff generation in vegetable garden lead to agricultural non-point source pollution in lakes. Although the N,P concentration of dry land is obviously lower than other types of soil, from the figure of runoff, we can see no vegetation on the land is unreasonable and wasting the resource.

Therefore, the government should promote the farmer returning farmland to tree forest and grassland based on the quantitative analysis above. All of the data and analysis provide a technical basis for the following economic policy for Lake Qiandao case analysis. 


\section{Chapter 6 Case analysis of agricultural non-point source pollution of Qiandao Lake}

\subsection{The main reasons and influence factors of ANPSP of Qiandao Lake}

Research shows that the agricultural non-point source pollution of the upstream watershed of Qiandao Lake reservoir (water source protection areas) is mainly as follows: soil erosion, livestock and poultry breeding pollution, chemical fertilizer and pesticide pollution (Chun'an Department of environmental protection, 2011).

(1) Soil loss

In the hills of fruit and animal husbandry area of Lake Qiandao, the population, reclamation rate, and multiple cropping indexes are all very high. The area of arable land accounts for $9.6 \%$ of the total land area and the area of fruit forest accounts for $74.1 \%$ of land area. Population density is large, and the land use of industrial land is more, so that the land reclamation rate is up to above $74 \%$, and multiple cropping indexes are more than $140 \%$. Excessive tillage increased soil turning, thus making the soil structure loose, and in the rainfall runoff effect, sediment, nutrients and other harmful substances can easily lose. The soil loss area in this area is $932.45 \mathrm{~km}^{2}$, which accounts for $60 \%$ of the total area (Chun'an Department of Statistics, 2011).

(2) Pollution from livestock and poultry

Over the past ten years, the agricultural structure in the region has obvious adjustment. Residential construction and rapid development and output value of animal husbandry, livestock and poultry breeding industry and the proportion in agriculture have increased obviously. However, with the development of the livestock industry, livestock and poultry excrement pollution are increasing. The pollution is mainly in the:

a. Livestock and poultry pollution and sewage are discharged everywhere.

b. Although the manure produced by the livestock farm is reused by the farmland, the manure is not processed through harmless treatment. According to the research, the actual load of livestock manure in the area is over the required nutrients and excess nutrients of manure and toxic and harmful substances enter into the water through runoff. The pollution loss amounts of 5 countries of Jiekou watershed in 2011 are: TP is $86543.13 \mathrm{~kg}$ and TN is $42356.45 \mathrm{~kg}$ (Chun'an Department of Statistics, 2011)

(3) Chemical fertilizer and pesticide pollution 
The statistical results show that this area is the main agricultural area of Qiandao Lake upstream watershed. The area of arable land accounts for $68.9 \%$ of total arable land in the upstream of Lake Qiandao Basin. From 1991 to 2011, amount of application of a pesticide fertilizer in the region continued to raise, after 1999, fertilizer and pesticide application amount has decreased according to statistics (due to the grain crop acreage reduction). But according to the investigation, in the water source protection, the amount of chemical fertilizer and pesticide at present is not restricted. The unit area $\mathrm{N}$ fertilizer application amount (active ingredient) is still as high as $454-698 \mathrm{~kg} / \mathrm{hm}^{2}$. According to the research, the fertilizer nitrogen loss of this area accounts for $79 \%$ of the total nitrogen loss of the upper stream and phosphorus loss accounts for $88.3 \%$ of the total loss of phosphorus fertilizer (Chun'an Department of environmental protection, 2012).

For all the problems of the agricultural non-point pollution of Qiandao Lake above, the government indeed establishes a lot of policy measures, but how the effects and implementation of each policy are still not sure. Therefore, this paper will put forward the policy suggestions and ideas according to the regional natural, social and economic status and water environmental planning.

\subsection{Specific policy analysis of Qiandao Lake}

Different watershed pollution control policy should have different effects in different areas. If the watershed is in social and economic developed area, and the agricultural non-point source pollution is serious (such as Taihu). The government can adopt pollution control policies of reward and punishment equally. In which the pollution fees and agricultural chemical use fees are not for the purpose of increasing financial income, the fundamental purpose is to change the farmer's behavior. In the developing area, the main pollution type is ANSPS (such as Qiandao Lake, Miyun Reservoir), the government should adopt the subsidy policy to guide and encourage the farmers. As long as the policy has a reasonable standard, the farmers are willing to accept.

In the situation of Lake Qiandao, first the government should do everything to improve the income of farmers and reduce the burden of production based on the principle of 'take less, give more'. Secondly, for a long time, Chun'an County sacrifices a lot of economic benefits for the better quality of drinking water of Zhejiang Province. Its economic development mainly relies on agriculture, thus restricting the development of industry. Compared with other rural areas in Zhejiang Province, the farmers' income and economic level are very backward (Wenzhang D 2000). Therefore, the agricultural non-point source pollution prevention and control of Qiandao Lake should use economic incentive policy as the main method and punishment tax as a supplement. 


\subsubsection{The establishment of the goal of economic policy}

The ultimate goal of the implementation of environmental economic policies is to achieve social welfare (economic benefit and environmental benefit maximization). So the goal of using economic means to control agricultural non-point source pollution is the manager should establish environmental total capacity control system and use price, cost, profit, credit, interest tax and other economic levers, and the responsibility system of environmental economic method to provide a flexible alternative for economic policy or several mixed economic policies to the farmers according to the national ecological laws and economic laws. The manager should adjust or change the production and lifestyle of the farmers to encourage and guide them to choose sustainable agricultural production method and healthy life. At last, in the precondition of the realization of non-point source pollution reduction in the watershed, the government should reach the social welfare maximization (or the optimal cost benefit ratio).

\subsubsection{The design principle and standard of the economic policy}

On the basis of the viewpoint and method of environmental management, environmental policy and environmental economics theory, in this paper, the formulation of agricultural non-point source pollution economic control policy should adhere to the following basic principles and standards.

The goal of formulating agricultural non-point source pollution control economic policy is controlling the basin water environmental total capacity, limiting and changing the production and lifestyle that are harmful to the environment based on the use of incentive. The encouragement and guidance for farmers to take the ecological environmental protection and sustainable agricultural road are necessary.

(1) The government should pay the subsidies to farmers who returned the farmland. According to research, in the water resource protection zone of Qiandao Lake, the returned farmland mainly has following uses: 1) Fallow. 2) Planting fruit trees and other economic trees, such as chestnut. 3) Planting timber forest and forage (Chun'an County Environmental Protection Committee, 2009).

For farmers who must return their farmlands, they have lost the most basic source of livelihood, so the government should pay compensation for the losses of stopping the cultivation of crops. At present, the compensation standard for the farmers who have changed the planting structure is $140 \mathrm{~b}$ rice or flour per mu plus 20 yuan in cash, but farmers reflect the compensation is too little.

According to the statistical data, now the summer crops of Chun'an are winter wheat and the average output per mu is $271.61 \mathrm{~kg}$ for years. According to the current wheat price $(2.3$ yuan $/ \mathrm{kg}$ ), the income is 624.703 yuan. So the net revenue is about $440-490$ 
yuan except for the production input (seeds, fertilizers and pesticides). The autumn crops are mainly rice and the average yield per mu in the region is $203.12 \mathrm{~kg}$ (Chun'an County Department of Agriculture 2011). According to the current rice price (3.06 yuan $/ \mathrm{kg}$ ), the income is 621.55 yuan. So the net revenue is about $430-510$ yuan except for the production input. For the whole year, profit loss of a farmer is 860-1000 yuan per mu in this area. So the government should use this as a standard for subsidy.

The compensation period for fallow or leased farmland should be determined according to the fallow or lease time. For farmers who change their farmland to tree forest or timber forest, the compensation period should be between 3-5 years.

(2) For the farmers who continue to engage in crop and extensively use fertilizers in the water source protection areas, on the one hand, the government should strictly control the sale and transport of the chemical fertilizer. On the other hand, the government should pay subsidies to those farmers who are no longer using chemical fertilizer in the crop cultivation process. At the same time, the government should establish the organic agricultural production demonstration area in the local area and use the successful production examples to show the advantages and prospects of the harmless organic agricultural production. Promote economic and technically feasible clean agricultural production technologies to the local farmers, thus changing the existing mode of production and ultimately achieving the goals of reduction of ANPSP.

The subsidy standard should be decided based on the relationship between the grain yield and fertilizer use. Use the formula to get a marginal profit under the circumstance of different amount of fertilizers. The marginal profit loss caused by the decreasing fertilizer is the subsidy standard.

Use the study (Huanchun 2010) of five villages of Jiekou watershed of Qiandao Lake in the period of 1999-2009 to get the relationship formula between grain yield and the fertilizer application, the expression is:

$$
\begin{gathered}
Y=2400.75+24.365 x-0.0569 x^{2} \\
R^{2}=0.9238
\end{gathered}
$$

Where: $\mathrm{Y}$ is autumn grain unit yield $\left(\mathrm{kg} / \mathrm{hm}^{2}\right)$

$\mathrm{X}$ is $\mathrm{N}$ fertilizer application in unit area $\left(\mathrm{kg} / \mathrm{hm}^{2}\right)$

At present, the region's summer planting area decreased greatly. Food crops are mainly autumn crops (such as grain). The average amount of fertilizer is about $310 \mathrm{~kg} / \mathrm{hm}^{2}$ and the average yield per unit area is about $319.04 \mathrm{~kg}$ per $/ \mathrm{mu}$ (Chun'an County Department of agriculture 2011). If there is no application of fertilizer, according to the formula, the average amount of autumn yield is only $160.05 \mathrm{~kg} / \mathrm{mu}$, grain output loss is about 
$158.99 \mathrm{~kg} / \mathrm{mu}$. According to the grain price, reduced income is about 190.79 yuan / mu, minus the fertilizer saving cost, the actual reduction in revenues is about $130 \mathrm{yuan} / \mathrm{mu}$. Therefore, the subsidy should base on this standard.

(3) For livestock and poultry pollution in the breeding area, it is advisable to take the following policies to control the pollution:

1) The government should increase the inputs of the livestock breeding environment management and shift the previous encouraging production subsidies to environmental protection subsidies. The government should promote and encourage the construction of livestock and poultry manure processing factory and compound organic fertilizer production through free or low interest loans and other preferential policies. The government should support and encourage livestock and poultry manure treatment industry and commercial organic fertilizer enterprises such as implementation of dutyfree and other aspects of the preferential policies.

2) Through subsidies, the harmless organic fertilizer can quickly use the existing fertilizer supply and marketing network to enter the market and reduce the commercial organic fertilizer market selling price. At the same time, the subsidies increase the market competitiveness of organic fertilizer and guide farmers to use of harmless organic fertilizer.

3) The government should charge for livestock and poultry farms pollution when it exceeds the standard. At present, the cost of using the chicken manure fermentation tower to treat poultry is about 90 yuan/t (Zhejiang Environmental Protection Bureau 2002), cattle and sheep manure processing cost in this region is about 70 yuan /t. There are many methods to treat the livestock wastewater. The government should choose the methods based on a low investment, low operation cost, a good treatment effect, and a convenient management technology.

\subsection{The feasibility of economic policy for agricultural non-point source pollution}

The agricultural non-point source pollution control and management are difficult and complex issue, the use of economical means to control non-point source pollution will be restricted by many factors. The practical policy is closely related to a country or basin scale of agricultural production, the level of technology, farming, natural, social economy, environmental and the process of environmental legislation.

(1) For the upstream watershed of Qiandao Lake, take the economical means has advantages for controlling the agricultural non-point source pollution.

Lake Qiandao is the only source of surface water to Zhejiang Province. The state and Zhejiang government always attach a great importance to the protection of the 
ecological environment of the water area. The government increased the investment support and promoted the construction of the ecological environment of the local area. The measures include the construction of ecological agriculture demonstration area, the vigorous creating of water conservation forest, and taking technical measures to carry out comprehensive management of small watershed. All of these measures have made obvious ecological and economic effect. In order to improve the water quality of the reservoir, the River Water Conservancy Commission and Zhejiang Water Conservancy Bureau jointly establish a regulation called Water Resources Sustainable Utilization Planning of Zhejiang Province in the twenty-first Century. It clearly puts forward that the government should strengthen the investment rate of upper stream water pollution prevention and control, soil erosion control and other aspects of the investment. In the upstream area, the government should apply cleaner production, pay attention to the control of agricultural non-point sources pollution, and promote the acceleration of livestock and poultry breeding wastewater treatment and establish and improve the management system of the livestock and poultry pollution. The government should also pay attention to the role of non-engineering measures, give full play to the role of the market mechanism in water resources protection and allocation, and use incentive policy, thus establishing a virtuous circle of development, utilization, protection and management of the water resources.

In the Qiandao Lake Basin, from the end of 2003, Zhejiang Water Conservancy Bureau started to take a series of important measures to protect Zhejiang's 'water of life'. The first project is the construction of the protection area of ecological water and natural restoration in the upstream before 2008. It is prohibited land farming and business activities below the water line of $155 \mathrm{~m}$. In the water conservation areas, it is banning the use of chemical fertilizers and pesticides. All of these planning and measures provide a policy basis for the government's adoption of economic incentive policies for agricultural non-point source pollution control in Qiandao Lake.

In addition, the government of Chun'an County could recognize the significance of developing ecological agriculture and protecting the ecological environment from a macro perspective. They actively lead the local people to take ecological agriculture and organizationally establish ecological environment construction. The investigation shows that the local farmers all have the awareness of environmental protection, but they lack the understanding of harm of the existing agricultural unreasonable production to the environment. Also, there is a lack of strict restraint policy and actively guide. Therefore, there are still considerable agricultural pollution sources in water protection zones. The Farmers said if the government provides preferential policies and technologies, they will actively choose economical mode of agricultural production that is conducive to the environment (Chun'an County Environment Protection Department 2009). 
(2) For other key basins in China, from the economic, technical, institutional point of view, the implementation of controlling agricultural pollution based on economic incentive policy is feasible.

1) Economic feasibility

The principle and the starting point for the formulation of the agricultural non-point source pollution economic control policy are to optimize the total social benefit. The ultimate result of an implementation of the economical means will be the obtaining of the net social benefit, including the environmental benefits.

Agricultural non-point source pollution is vast in area. It has involved a variety of public individuals in China, so use the command and control management will spend a lot of manpower and material. However, use economical means to stimulate the public through the behavior selection of conscious participation in pollution control, which can save the management cost, while getting the environmental benefits.

Tax while in some period increased the production cost of farmers, may also make crops production and income decrease. From the long-term development perspective, the change of the mode of production and behavior will make the farmers get more benefits. The reason analysis is as follows:

a. The consumer's awareness of environmental protection and self-protection consciousness is increasing. People require safe and high quality agricultural products. When they are in the face of contaminated agricultural products and organic agricultural products, most consumers are more willing to buy the organic one at a high price. At present, organic food prices in China are 1 to 3 times higher than the general food prices. So, in the case of no application of fertilizers and pesticides, even if the agricultural output will decrease, the real income of the farmers will not be reduced.

b. Adopt the scientific and reasonable agricultural production technology and mode of production, improve the utilization of material and energy efficiency, can also produce high crop yield and increase the income of farmers.

c. Many environmentally unfriendly agricultural means of production have green alternatives with similar or even lower prices, but the better effect. The use of these products can protect the environment and improve the yield and quality of agricultural products.

d. The processing of manure of large-scale livestock farms can realize the organic fertilizer production industrialization and generate great economic benefits. If the analysis is based on the cost benefit of production enterprises, it can increase profit of $40-50 \%$ after the livestock and poultry excrement processing. If the analysis is based 
on the production efficiency, the commercial organic fertilizer can increase the utilization rate of $10-15 \%$, the fertilizer ratio of input and output of organic fertilizer is $20 \%$ higher than the chemical fertilizer (Tianyu 2000).

2) Technical feasibility

Chinese researchers have mastered many accurate calculation methods of water environmental capacity and feasible total pollution load allocation method. Also, many important basins have the agricultural technical facilities and capabilities of timely and comprehensive monitoring of non-point source pollution. GIS technologies strongly support the application of a variety of non-point source pollution load calculation model mature application. It can let the environment researchers find out the base of ANPSP, the quantitative relationship between an important watershed and all kinds of agricultural non-point source pollution, environmental impact assessment, and environmental profit and loss as soon as possible. All of these can provide basic data for the formulation of agricultural non-point source pollution control of economic policy.

In the aspect of the specific technical measures of agricultural non-point source pollution control, China has done a lot of very fruitful research and practice, which make the farmers apply ecological and environmental protection production mode instead of unreasonable production behavior. Also, the government promotes the application of advanced engineering measures for the control and reduction of agricultural non-point source pollution.

In the aspect of field management, China has a long history and rich heritage of farmland management technology. China has created many brilliant achievements and accumulated excellent experience in many aspects, such as crop rotation, intercropping, combined agriculture and animal husbandry, and the integrated pest management. Organic agriculture is also inspired by Chinese traditional agriculture and uses it as the basis for the development of organic agriculture technology. The organic agriculture technology is also developing and promoting rapidly in China. In addition, China has achieved prominent result on ASPSP control through returning farmland to forest and grassland, contour tillage, strip planting, the optimal allocation of land use, decreasing agricultural runoffs. With the rapid development of animal husbandry and comprehensive utilization of livestock and poultry manure processing technology, especially with the further improvement of biological technology and related machinery and equipment, the livestock and poultry manure processing technology will shift to high efficiency and low energy consumption mode. All of these can improve and promote the development of organic agriculture.

In agricultural pollution control engineering technology, scientists have done a lot. Such as, build the dam, flood intercepting ditch, gully protection in the soil and water 
loss area and strong erosion area. Construct the reservoir buffer in the lake tributaries natural catchment area. Treat domestic wastewater and farmland wastewater through planting plants cultivated wetland and oxidation pond (Xiangcan 2001).

\section{3) Legislation security}

a. Environmental economical means is becoming an important tool in environmental decision-making and environmental management in China

China twenty-first Century Agenda puts forward that the government should make full use of economical means and market mechanism to promote sustainable development. The government should add the environmental costs into the economic analysis and decision-making process while changing the previous method of freely using the environment and putting environmental costs onto society. The government should promote sustainable economic development in the use of economical means and the market mechanism by adjusting the various economic policies at the national macrocontrol. The main activities include: to reduce all kinds of subsidy policies that are not matching the sustainable development goals. The government should reform the existing economic and fiscal incentives to meet the goal of sustainable development. The government should establish a policy framework and promote the establishment of a resource allocation mechanism of pollution control. Establish the price system that is suitable for the sustainable development and reform the irrational price system. The government should establish the environmental tax policy, policy of resource use fee, and resource pricing system that is suitable for China's national conditions. Give certain preferential tax to the environmental protection and ecological restoration project.

Chinese Environmental Protection 'ten-five' Plan pointed out that the government should promote the environmental protection tax reform actively and charge for the products that are harmful to the environment. The government should use the existing tax to adjust the resource allocation and protect the environment in the macro-level. The government should promote the implementation of charging system of pollutant discharge, set reasonable fees, use incentives to combine the public welfare of environmental protection and competition of the market economy. The government should establish a system that the whole society has the consciousness to protect the environment through economic laws and regulations, mandatory regulations, comprehensive use of administrative management, public voluntary and other means.

b. Agricultural non-point source pollution has caused all levels of government and environmental protection departments concerned

The Chinese government is aware of the rural ecological environment crisis, has put the governance and improvement of the rural environment into the work schedule. The 
Chinese Environmental Protection Administration has added the agricultural non-point source pollution control into the project budget in the three rivers and three lakes water pollution prevention and control 'ten five' plan. Many areas have banned the use of chemical fertilizer and pesticide for the protection of local water resources and the water environment. For the rural large-scale livestock and poultry pollution, the Chinese Environmental Protection Administration has respectively in 2002 and 2003 officially released the 'technical specifications of livestock and poultry pollution prevention and control' and 'discharge standards of livestock and poultry breeding pollution', which provide the basic conditions for the use of economic instruments of ASPSP control.

c. Agricultural non-point source pollution prevention and control are in coordination with the present agricultural policy of China

Some pollution control policies (such as taxes) might increase the cost of production of farmers within a certain period of time, but its fundamental purpose is not to increase financial revenue, but to stimulate farmers as soon as possible to give up the unreasonable production and choose sustainable agricultural production methods and technology, which is environmental friendly and achieving higher economic benefits.

Chinese Premier Jiabao Wen emphasized the importance of the development of agriculture, rural economy, social development and the development of agricultural production and ecological environment protection. He pointed out that the government should pay attention to the change of the mode of economic growth and establish the method of developing the speed, structure, quality, and benefit at the same time. The government should make policy based on saving resources and protecting the environment. Therefore, the formulation and implementation of practical economic policies to control agricultural non-point source pollution are consistent with the government's "sustainable agriculture" policy. 


\section{Chapter 7 Conclusion and prospect}

\subsection{The research content summary}

In this paper, research methods and progress of domestic and foreign agricultural nonpoint source pollution are reviewed by reading a large number of references. In the study, a typical small agricultural watershed ---Jiekou watershed of Qiandao Lake has been chosen. Runoff, $\mathrm{N}$ and $\mathrm{P}$ concentration of different land use types are monitored and analyzed to provide the scientific basis and effective experience for comprehensive management of Qiandao Lake. At the same time, the reasons for agricultural non-point source pollution are given. At last, the agricultural non-point source pollution control policy model is put forward based on governance policy, environmental legislation, technical system and subsidy policy. Further, the subsidy policy is analyzed in details and can be divided into three types according to the difference: the subsidies of the positive externality, the subsidies of reducing the negative externality and price subsidies. Specifically, case analysis of Jiekou watershed of Qiandao Lake was taken. The paper puts forward the watershed agricultural non-point source pollution control of economic policy according to the specific situation of the river basin on the theory basis of policy frame, while analyzing the feasibility of economic, technical and legal system. The main conclusions are as follows:

(1) Agricultural non-point source pollution has become the main pollution sources of water pollution in China. Agricultural non-point source pollution load ratio has been close to or more than $50 \%$ in many watersheds. Different basins have different natural conditions and social production status, so the characteristics and dominant factors of agricultural non-point source pollution have different effects. On the whole, China's agricultural non-point source pollution is mainly caused by human factors, which are including soil and water loss caused by the unreasonable land use, excessive agricultural chemical application, large-scale livestock breeding pollution of rural life, indiscriminate discharge of wastewater, the separation of national agricultural policy and agricultural environmental management, especially is the lack of corresponding regulations and methods for the supervision of agricultural non-point source pollution control.

(2) Quantitatively analyze the relationship between the pollution and soil types. Crop coverage and soil conditions of different lands are different, so the rainfall runoff characteristics have obvious differences. Runoff volume of dry land is the most. $\mathrm{N}$ and $\mathrm{P}$ concentration of the vegetable garden is the most. The conclusion is that farmers should return the farmland to tree forest and grassland for the control of ASPSP. The data analysis provides a technical basis for the establishment of the economic subsidy policy. 
(3) In this thesis, the economic policy framework system of agricultural non-point source pollution control is 1) governance policy based on guiding function, including maintaining the self-sufficiency rate, reasonable layout and the construction of the technology organization. 2) Environmental legislation based on constraint function, including regulation of the control of organic waste emission, regulation for promoting the development of water recycling, regulation for the control of pesticide pollution. 3) Technical system, including the overall monitoring of quality and environmental capacity of farmland, establishing the efficient technology promotion system and promoting the efficient fertilization technology. 4) Subsidy based on guiding and encouraging function, including reducing subsidies of the negative externality and increasing positive externality and other preferential policies (investment or to provide low interest, interest free loans, tax relief). The implementation goal of the policy is to minimize the cost benefit ratio to achieve specific implementation of agricultural nonpoint source pollution reduction targets and water environmental quality standards.

(4) The function and effect of each policy are different. Generally, the implementation of tax policy is the most common. Its function is to 'block' and its effect is more outstanding. Sewage charges are suitable for the control of livestock and rural village life pollution. Input tax and product use tax can control excessive application of chemical fertilizer and pesticide of farmland. The function of subsidies is to 'dredge'. Although its effect is not ideal and fast as tax means, the combination of taxes and subsidy's reward and punishment simultaneously can decrease the non-point source pollution.

(5) Because China is vast in area, the difference of regional natural conditions, agricultural production and social and economic development level is of great. Different watershed pollution control policy should have different effects in different areas. If the watershed is in social and economic developed area, but the agricultural non-point source pollution is serious (such as Taihu). The government can adopt pollution control policies of reward and punishment equally. In which the pollution fees and agricultural chemical use fees are not for the purpose of increasing financial income, the fundamental purpose is to change the farmer's behavior. In the developing area and the main pollution type is ANSPS (such as Qiandao Lake, Miyun Reservoir), the government should adopt the subsidy policy to guide and encourage the farmers. As long as the policy has a reasonable standard, the farmers are willing to accept.

Qiandao Lake is the "water of life" of Zhejiang Province. The government should ensure the economic and social sustainable development of Zhejiang to stabilize and improve the water quality of Lake Qiandao. The government should give full consideration to the natural, economic, and social development of water protection areas while matching the related policy measures. The article thinks that the economical policy of agricultural non-point source pollution in the basin should be 
based on subsidies, tax reduction and exemption, credit and compensation to guide and encourage farmers to improve land utilization structure, reduce the use of chemical pesticide, and promote the use of harmless organic fertilizer, support the manure treatment industry and commercial organic fertilizer production.

(6) There are many difficulties and obstacles in the formulation and implementation of agricultural non-point source pollution control economic policy, but with the development of comprehensive environmental protection work as well as the improvement of an economy, technology and system, in key river basin and water environment function zone, the formulation and implementation of incentive pollution control policies is feasible.

\subsection{Problems and suggestions}

(1) The agricultural non-point source pollution controls economic policies system provided in this paper is preliminary from the theoretical model analysis and the practice in China. China is vast in territory and the natural conditions and economic activity differs in thousands of ways. Agricultural non-point source pollution situation is different in different areas. Therefore, it is not science and not feasible to formulate a unified and suitable policy of ANPSP control for the whole area. The government can authorize local government to establish a watershed management control policy.

(2) Specific policies formulated on the basis of the theoretical model need a large number of accurate data to support. Investigation and study on agricultural non-point source pollution are still very weak in China. The lack of accurate enough basic data is the biggest obstacle to develop management strategies and it is easy to lead to blindness and uncertainty of macro decision. The paper suggested that China should strengthen the systematic investigation and study on agricultural non-point source pollution, including the study of the relationship between the agricultural non-point source pollution and water body response based on watershed unit. Establish the study of transformation laws of fertilizer and pesticide based on the ecological unit. On the one hand, the government should strengthen the monitoring. On the other hand, the government should establish or adopt the accurate model to calculate (rather than estimated the) the actual pollutant generation, loss, and capacity into the river. Further, find out the main cause of non-point source pollution and the way of pollution source, pollution load contribution rate and the environmental economic loss. These are the fundamental basis for the formulation of economic incentive policies.

(3) China is in the economic transition period and the market mechanism is not perfect. In the control of agricultural non-point source pollution, economical means can play its role when combined with other management means, such as using the regulations as security and technology as support, and education as the basis. 'Government + market 
+ farmer' is the comparatively successful policy model. The specific practices are as follows:

In the control of the key polluted area, the government should be as soon as possible added the non-point source pollution (especially the agricultural non-point source pollution) into the plan of total quantity control and seek the fair pollution load allocation method. The government should accelerate the use of agricultural chemicals legislation, the formulation of pesticide standards, standardized application technology control, and the establishment and improvement of land soil protection law.

The government should strengthen the education of sustainable agricultural development and agricultural non-point source pollution hazards and prevention measures of the local farmers. The government should pay attention to a new model, environmental protection and agricultural production technology development. Apply and popularize the ecological agricultural technology. Establish ecological demonstration area and let a farmer be aware of the benefits of ecological agriculture. Promote organic food and green food certification. Focus on rural domestic sewage and waste management.

For a given agricultural non-point source pollution control target, the government can adopt various methods to achieve, including the combination of various management measures and engineering measures, the best scheme should be evaluated through comprehensive environmental economic cost-benefit system.

(4) With the further adjustment of agricultural production structure and the structure of agriculture in the Lake Qiandao water source protection area, livestock and poultry breeding industry will become the main source of pollution in this area. The government should strengthen the sewage monitoring, and as soon as possible to study and master the ways and laws of livestock and poultry pollution loss. The government should study accurately the impact of such pollution on water quality and quantify the damage to the environment (especially water environment), and provide a reliable basis for making more effective pollution control measures and policy measures.

\subsection{The innovation of the thesis}

(1) This thesis studies the theoretical foundation of ANPSP control in rural areas and puts forward an integrated framework of ANPSP prevention and control. At the same time, the paper's principle and control methodology of ANPSP focus on many fields, such as economics, social science and mathematics.

(2) The spatial scale selection of studies is properly compared with other scholars mainly focusing on the large scale rural areas of the province and even the country. The thesis analyzes both social economic factors and the factors of nature. 
(3) The paper put forward many policies and legislation of agricultural non-point source pollution. Further, the supervision system of source control and the corresponding incentive mechanism is provided.

\subsection{Research prospects}

Combined with the actual needs and existing research on agricultural non-point source pollution prevention and control of rural environmental problems in the future, the paper thinks that the focus on rural environmental pollution prevention and control in China lies in the following aspects:

(1) The study of ANPSP should integrate theory framework and expand the research ideas. The study should strengthen collaboration among multiple disciplines based on the existing research. Especially strengthen the research on the environmental pollution mechanism and control process. The researchers should summarize the research progress of the theoretical framework and establish the theoretical framework of rural environmental pollution prevention and control system.

(2) The choice of the influence factors should be the multi-factor. At the same time, add the restricted factors into the research.

(3) Processing method of data is very important for improving the credibility of research results, consistency, completeness and reliability of the data in the study. Future research should focus on the quality of data and to standardize the data processing.

(4) To improve the standard of quantitative research of agricultural non-point source pollution status and degree. First, make sure that each evaluation index is feasible at the theoretical level and build up the quantitative system corresponding with resources and environment in rural areas. In the formulation of a quantitative standard, at present there are two main methods, one is using standards established by country as a reference, and the other one is using ideal condition of the rural environment as a reference standard.

(5) In the aspect of spatial scale, most of the scholars in China mainly concentrated in the provincial and even national scope. So how to let a space scale extend downward, follow the principle of "from the nature to the human society, from the big area to a small area", so the conclusion is more targeted will be a key point in the future research. 


\section{Reference}

1. Ailing Yang, Environmental non-point source pollution study of surface water [J]. Environmental Science, 1999, 7(5) Pages: 60 - 65.

2. Xing G X, Zhu Z L. The assessment of nitrogen loss from agriculture fields in China [J]. Nutrient Cycling Agroecosysterms, 2000, 57(1) Pages: 67-73.

3. Environmental Protection Department of Chun'an County. Research on Countermeasures to protect the rural ecological environment of Qiandao Lake basin, 2000

4. Arkansas, NPS Management Program Update Effective Date [M], 2005

5. Guoyan $\mathrm{Xu}$, Analysis of present situation of agriculture ecological benefits and Countermeasures of the Chun'an County [J]. 2000 Pages: 5-6

6. Zongshe Zhang, The relationship between Lake Eutrophication and Aquatic plants [J]. Lake Science, 1998, 10 (4) Pages: 83-86

7. Xu Y H. Straw incineration pollution and countermeasures of China [J]. Environment and Sustainable Development, 2007, (3) Pages: 21-23.

8. Lishan Ma. Agricultural non-point source pollution and Its Control Countermeasures of Tai Lake [J]. Environment Science.1997, 17(1) Pages:3947

9. Lena B V. Nutrient preserving in river in transitional strip [J]. Journal of Human Environment, 1994,3(6) Pages:342-347

10. Foy B H, Withers P J A. The contribution of agricultural phosphorus to eutrophication [J]. Proceedings of fertilizer society, 1995 Pages :356

11. Sharpley A N, Chapra S C R, Wedepohl R, Managing agricultural phosphorus for protection of surface waters, issues and options [J]. Journal of environmental quality, 1994(23) Pages: 427-451

12. Hongxiang $\mathrm{Hu}$, Tian Hong, Youhua Ma. Agricultural non-point source pollution and its control strategy [J]. Chinese Agricultural Science Bulletin, 2005, 21 (4) Pages: 315-347.

13. Quansheng Bao. Progress in research in aquatic environmental non-point source pollution in China (J). Journal of Environmental Sciences, 1997, 9(3) Pages:329-336

14. The Department of Environmental Protection. The three rivers and three lakes water pollution control planning [M]. Beijing: China Environmental Science Press, 2000

15. Hongliang Liu. Lake Eutrophication in China [M]. Beijing: China Environmental Science Press, 1990 Pages: 21-40 
16. Weaver D.M., Reed A.E.G. Patterns of Nutrient Status and fertilization on Soils of the South Coast of Western Australia [J]. Agriculture Ecosystem and Environment 1998, 67 Pages: 37-53

17. Huanlei Lee. Non-point Source Pollution Model Progress and Development Trend [J]. Water Resources Protection, 1996, (2) Pages: 14-18

18. Quansheng Bao, Huaer Yu. Water Environment Non-point Source Pollution Research and Prospect [J], Geography 1996,16 (1) Pages :66-72

19. - Yang Hu. Non-point Source Pollution Model Progress and Development Trend [J]. Water Resources Protection, 2004, (4) Pages :10-18

20. Dago G., Hessenetal V. The significance of loss of nitrogen of eutrophication in marine receptors and freshwater. AMBIO - Human Environment, 1997,26 Pages: $306-313$

21. Lu Yao, Southern Jiangsu Taihu Basin agricultural non-point source pollution and agricultural sustainable development strategies [J], Environmental Science Dynamics, 1998 (2) Pages: 1-4

22. Anthony C. Resource and Environmental Economics [M]. London: Cambridge University Press, 1981 Pages:189-194

23. Abler D G, Shortle J S. Technology as an agricultural pollution control policy [J]. America Journal of Agricultural Economics, 1995,158(77) Pages:20-32

24. Fan Zhang, Environmental and natural resource economics[M], Shanghai: Shanghai people's Press, 1998 Pages : 119-123

25. Hongfu $\mathrm{Wu}$, Regional Agriculture Environment problem and the comprehensive governance in China [M]. Beijing: China Environmental Science Press, 2005, China Environ-mental Science Press, 2005 Pages: $43-45$

26. Dayong Hong, Reproduction of dual social structure: The sociological analysis of non-point source pollution in Chinese countryside [J] Sociological Studies, 2004, 7(4) Pages:1-7

27. Yuesong Lu, Rural ecological environment problems and the countermeasures for analysis in China [J]. Country agricultural farmer: B, 2009, 6 Pages :38-39

28. Haiyan $\mathrm{Wu}$. Study on the rural ecological environment problems of new rural construction [J]. Journal of Jiangxi Administration Institute, 2009, 11(3) Pages : 49-51

29. Zhizhong Tian, Externalities theory and the economics analysis of pesticide polution [J]. Chinese Agricultural Science Bulletin, 2005, 21(7) Pages: 448450 . 
30. Yali Lu, Huifeng Xue, Game analysis on the control of agricultural non-point source pollution in China [J]. System Sciences and Comprehensive Study in Agriculture, 2007, 23 (3) Pages: 268-271

31. Jie Shang, The economic analysis of rural ecological environment non-point source pollution [J], Heilongjia Social Sciences, 2007, 1 Pages: 74-76

32. Yuan Ping. Environmental economic study on agricultural pollution and its con trol: theoretical discussions and empirical analyses [D], Beijing: Chinese Academy of Agricultural Sciences, 2008 Pages: 36-38

33. Weiguang Yang, Yi Fu. Index and assessment method for quality of agro-ecoenvironment [J] Environmental Protection, 1999(2) Pages: 42-43

34. Lihua, Zhou. Study on the behavior of household management and ecological e nvironment [J]. Ecological Economy, 2002, 9 Pages: 27-31

35. Yan Ma, Farm households' behaviors and its eco-environmental effect [J]. Ecology and Environmental Sciences, 2007, 16 (2): Pages: 11-12

36. Xiaofang Le, Analysis on rural lifestyle to the rural environment [J]. Agroenvironment and development, 2004, 4 (1), Pages: 42-45

37. Hongxia Qin, Study on the villagers' lifestyle and rural environment problems: in case of port village [J]. Shanghai Economics Review, 2006, 7 (2): Pages: 90 95

38. Xiaodong Zhu. The problems of rural environmental under the background of $n$ ew rural construction [J]. Rural Economy, 2008, 24(4) Pages: 11-12

39. Binghui Zheng, Yongze Zhang. Improvement of ecological dynamics model of Dianchi [J]. Environmental Sciences. 1994, 7(4) Pages:1-6

40. Ailing Yang, Yanming Zhu. Surface Water Environmental Non-point Source Pollution [J].Environmental Science, 1999,7 (5) Pages: 60-67

41. Long Zhang, Jipin Zhuang. Agricultural non-point source pollution situation and development trend [J] CGE,1998,17(6) Pages:51-56

42. Yansheng Yang. Preliminary study of regional soil erosion prediction equation [J]. Soil Technology. 1990, 27 (1) Pages: 73 - 79

43. Zhaxian Wang, Watershed management information system [J]. Beijing: China Forestry Publishing. 1994, Pages: 120

44. Yibing Chen, ANSWERS soil erosion model and its application [J]. Agricultural Soil Paper. 1998, (2):28 - 32

45. Zhongge Wang, Changming Liu, Youbo Huang, principle, Structure and applied research of SWAT Model [J]. Progress in Geography, 2003,22(1) Pages: 79-86 
46. Dongmei Liu, Agricultural non-point source pollution control legislation of the United States and Japan and Its Enlightenment to China from the [J]. World agriculture, 2008 (4) Pages: 35-37

47. Line D E. Non-point sources [J]. Water Environment Research, 1993, 70(4) Pages: 844-912.

48. Thomas. T, Segerson, K and Braden, J. Issues in the Design of Incentive Schemes for non-point Source Pollution Control. Kluwer Academic Publisher, 1994,(6) Pages:2-10

49. Dubgard, A. the Danish pesticide program: success or failure depending on indicator price. Paper of world congress of environmental and resource economics. 1999

50. James S, Shortly, Richard D. Horan and David. G, Research Issues in nonpoint pollution control. Environmental and Resource Economics. 1998,11(3) Pages:571-585

51. Lizhi Zhu, Lijian ZHng, Hongkang LI. The compensation mechanism of controlling agricultural pollution in finance and market [J],

Finance and Trade Research, 2007, 18 (4) Pages: 17-22

52. Li'an Zhu, Jizeng Wang, Yaoguo Yao, et al. Nonpoint sources pollution from li vestock and poultry and ecological control[J]. Bulletin of Soil and Water Conse rvation, 2005, 25(2) Pages: 40-43

53. Ping'an Xiang, Yan Zhou, Ge Huang, et al. Discussion on the green tax stimula tion measure of nitrogen fertilizer nonpoint source pollution control: using the Dongting Lake Area [J]. Agriculture Science, 2007, 40(2) Pages: 330-337.

54. Jianchang Liu, Weiqi Chen, Luoping Zhang, et al. Environmental economic po licy designed to control watershed agricultural nonpoint pollution: a case study from Jiulong River watershed of Fujian Province[J]. Chinese Journal of Agricu lture, 2005, 13(3) Pages: 186-190

55. Zhengyong Yang. Theory of nonpoint pollution fishery endogenous and manag ement of environmental economic policy [J]. Productivity Research, 2004 9(2) Pages: 28-30.

56. Huanchun Lv. Study of non-point source pollution and ecological effects of agriculture of the Qiandao Lake. 2010

57. Jian Zhou, The harm of agricultural non-point source pollutants on agricultural environmental protection [J]. 1999,9(1) Pages:22-25

58. Shuilong Zhang, Current situation and development trend of researches of agricultural non-point source pollution [J]. Journal of ecology, 1998, 17 (6) Pages: 51-55. 
59. Yinxu Chen. Analysis of dynamic variations and origin of main pollutants in the Qiandao Lake [J], Journal of Zhejiang University (agriculture and Life Science Edition), 2002, 14(3) Pages:43-45

60. Dancheng Ni, Wenfang Huang. The policy analysis on the causes of agricultural non-point source pollution [J]. China Environmental Protection Industry 2009, 3(11) Pages : 29-34

61. Lipin Cao, Xiaoyan Wang. Economic means for water quality management [J]. Water Protection,2004,(20)3 Pages:33-36

62. Pin He, Jiaji Wang. The situation and challenge of agricultural non-point source pollution control [J]. Agricultural Environment protection, 1999,(18)5

Pages: 235-236

63. Malik A S, Larson B A, Ribaudo M. Economic incentives for agricultural nonpoint source pollution control [J]. Water Resource Bulletin, 1994, 30(3) Pages: 471-480

64. Shortle J S, Horan R D, Abler D G, Research issues in non-point pollution control [J]. Env and Res Econ, 1998, 11 Pages: 571-585

65. Xiaowen $\mathrm{Xu}$. The Enlightenment of green agricultural subsidies and agricultural pollution control of The United Stat

Finance and Trade Researches[J] Theory Exploration, 2006(4) Pages:69-72

i Huanchun Lv. Study of non-point source pollution and ecological effects of agriculture of the Qiandao Lake. 2010 